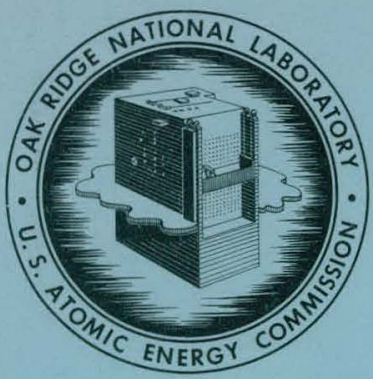

\section{OAK RIDGE NATIONAL LABORATORY}

operated by

UNION CARBIDE CORPORATION

NUCLEAR DIVISION

for the

U.S. ATOMIC ENERGY COMMISSION

ORNL - TM- 1990

SIMPLIFIED CALCULATIONS FOR SMALL DEFLECTIONS

IN WALLS OF RADIO FREQUENCY CAVITIES

L. N. Howell 


\section{DISCLAIMER}

This report was prepared as an account of work sponsored by an agency of the United States Government. Neither the United States Government nor any agency Thereof, nor any of their employees, makes any warranty, express or implied, or assumes any legal liability or responsibility for the accuracy, completeness, or usefulness of any information, apparatus, product, or process disclosed, or represents that its use would not infringe privately owned rights. Reference herein to any specific commercial product, process, or service by trade name, trademark, manufacturer, or otherwise does not necessarily constitute or imply its endorsement, recommendation, or favoring by the United States Government or any agency thereof. The views and opinions of authors expressed herein do not necessarily state or reflect those of the United States Government or any agency thereof. 


\section{DISCLAIMER}

Portions of this document may be illegible in electronic image products. Images are produced from the best available original document. 
This report was prepared as an account of Government sponsored work. Neither the United States, nor the Commission, nor any person acting on behalf of the Commission:

A. Makes any warranty or representation, expressed or implied, with respect to the accuracy, completeness, or usefulness of the information contained in this report, or that the use of any information, apparatus, method, or process disclosed in this report may not infringe privately owned rights; or

B. Assumes any liabilities with respect to the use of, or for damages resulting from the use of any information, apparatus, method, or process disclosed in this report.

As used in the above, "person acting on behalf of the Commission" includes any employee or contractor of the Commission, or employee of such contractor, to the extent that such employee or contractor of the Commission, or employee of such contractor prepares, disseminates, or provides access to, any information pursuant to his employment or contract with the Commission, or his employment with such contractor. 
Contract No. W-7405-eng-26

Ceneral Engineering Division

I. N. HowelI

JANUARY 1968

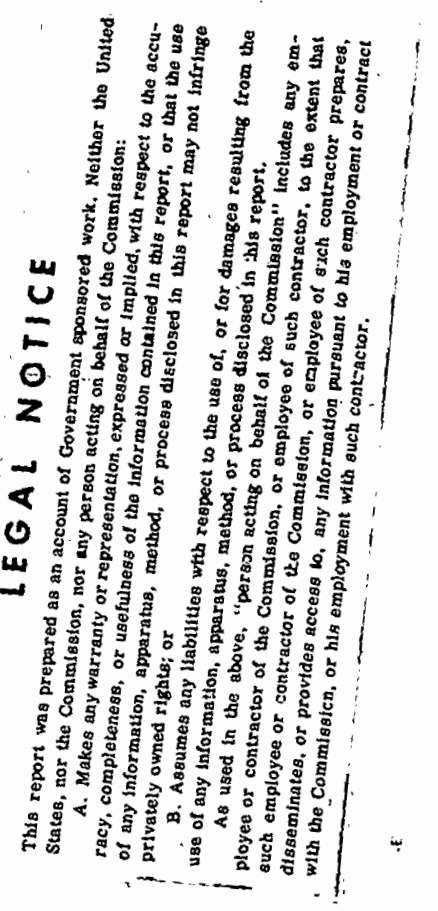

OAK RIDGE NATIONAL IABORATORY

Oak Ridge, Tennessee operated by

UNION CARBIDE CORPORATION

for the

U.S. ATOMIC ENERGY COMMISSION 
THIS PAGE

\section{WAS INTENTIONALLY LEFT BLANK}


CONTENTS

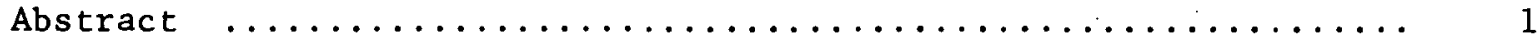

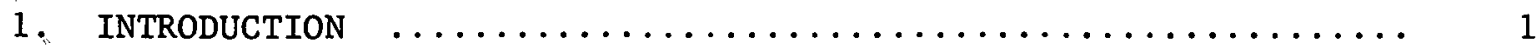

2. METHODS OF MATHEMATICAL ANALYSIS $\ldots \ldots \ldots \ldots \ldots \ldots \ldots \ldots \ldots$

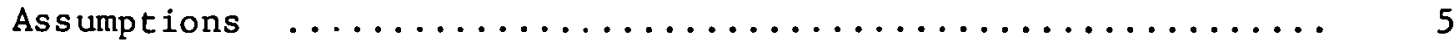

Equations Derived for Cavity without Side stays $\ldots \ldots \ldots \ldots \ldots .8$

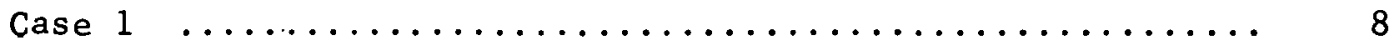

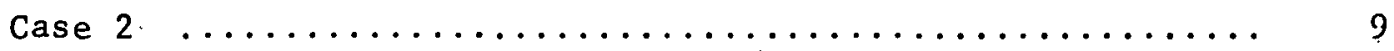

Equations Derived for Cavities with Side Stays $\ldots \ldots \ldots \ldots \ldots \ldots 9$

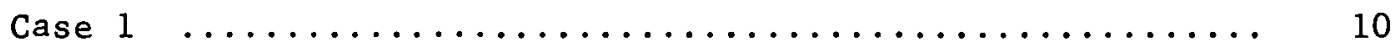

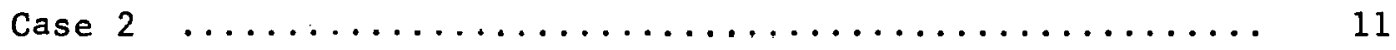

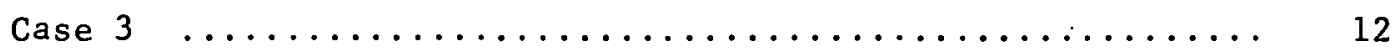

Panel Deflections, Moments, and Stresses $\ldots \ldots \ldots \ldots \ldots \ldots$

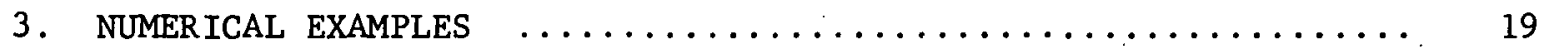

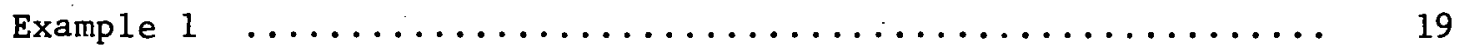

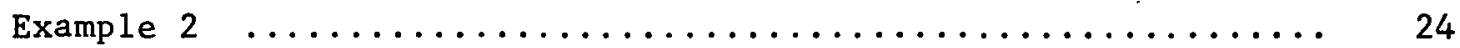

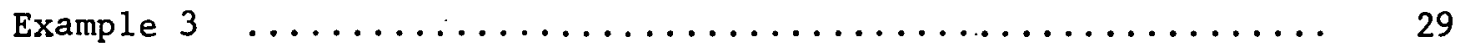

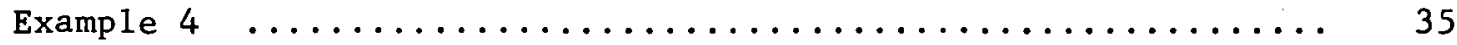

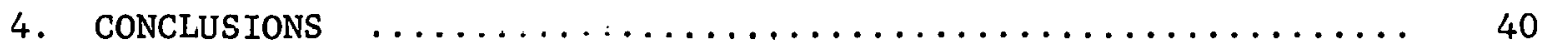

Appendix A. COMPOSITE WALL STRUCTURE CONSIDERED AS AN EQUIVALENT

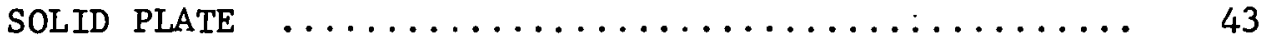

Appendix B. COPPER-CLAD STEEL PLATE CONSIDERED AS SOLID

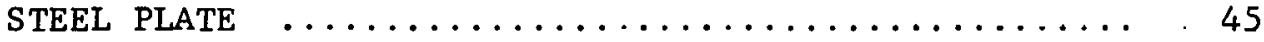

Appendix C. MATHEMATICAL DERIVATION OF ELASTIC CURVES, BENDING MOMENTS, AND END SLOPES FOR CAVITY WITHOUT SIDE STAYS

Appendix D. MATHEMATICAL DERIVATION OF ELASTIC CURVES, BENDING MOMENTS, AND END SLOPES FOR CAVITY WITH SIDE STAYS .. 53 


\section{THIS PAGE WAS INTENTIONALLY LEFT BLANK}


LIST OF TABLES

Table Number

1 PANEL Computer Program Output Data for Panel Deflections, Moments, and Stresses for Selected Values of Panel Lengths and Widths

2 Computer Program COAXCAV-5 Output for Reactions, Moments, and End Slopes for Widths at 10 Stations of the Double-Gap Cavity in Numerical Example 1

3 Computer Program COAXCAV-5 Output for Deflections at 10 Stations of Double-Gap Cavity in Numerical Example 1

4 Computer Program COAXCAV-3 Output for Widths, Second Moments of Area, Reactions, Moments, and End Slopes for the Maximum Deflections Specified at 11 Stations of Double-Gap Cavity in Numerical Example 2

5 Computer Program COAXCAV-3 Output for Deflections at 11 Stations of Double-Gap Cavity in Numerical

Example 2

6 Compuler Program COAXCAV-2 Output for Widths, Second Moments of Area, Reactions, Moments, and End Slopes. for the Maximum Deflections Specified at 11 Stations of Double-Gap Cavity in Numerical Example 3

7 Computer Program COAXCAV-2 Output for Deflections at 11 Stations of Double-Gap Cavity in Numerical Example 3

8 Computer Program CAVSAG Output Data for the SingleGap Cavity of Numerical Example 4
Page

Number

17

20

22

26

27

32

33

38 


\section{THIS PAGE}

\section{WAS INTENTIONALLY \\ LEFT BLANK}


1 Single-Gap Cavity with Flat Tapered Sides, Flat Parallel Top and Bottom, Flat Ends, and Side Stays for the Energy Region Above $100 \mathrm{Mev}$

2 Single-Gap Cavity with Flat Parallel Sides, Shaped Top and Bottom, Flat Ends, and Side Stays for the Energy Rcgion Above $100 \mathrm{Mev}$

3 Double-Gap Cavity with Flat Tapered Sides, Flat Parallel Top and Bottom, Cylindrical Ends, and No Side Stays for the Energy Region Below $100 \mathrm{Mev}$

4 Type Construction Assumed for Cavity Wa11s

5 Prototype of Radio Frequency Cavity for a 50-Mev Separated Orbit Cyclotron During Construction

6 Prototype of Radio Frequency Cavity for a $50-\mathrm{Mev}$ Separated Orbit Cyclotron After Addition of Stiffeners

7 Coordinate Axis for Maximum Deflection of Panel Determined by the Computer Program PANEL

8 Dimensions of Double-Gap Cavity Without Side Stays for Numerical Example 1

9 Deflection Pattern at Station 1 of Double-Gap Cavity of Numerical Example 1

10 Deflection Pattern at Station 5 of Double-Gap Cavity of Numerical Example 1

11 Deflection Pattern at Station 10 of Double-Gap Cavity of Numerical Example 1

12 Dimensions of Double-Gap Cavity Without Side Stays for Numerica1 Example 2

13 Deflection Pattern at Station 6 of Double-Gap

14 Deflection Patterns at Station 11 of Double-Gap 
15 Deflection Pattern at Station 1 of the Double-Gap Cavity of Numerical Example 3

16 Deflection Pattern at Station 11 of the Double-Gap Cavity of Numerical Example 3

17 Deflection Pattern for Single-Gap Cavity of Numerical Example 4

A.1 Cross Sections Through a Composite Wall Structure and a Steel Plate of Equivalent Thickness

B.1 Cross Sections lhrough a Copper-Clad Steel Plate and a Sulid Steel Plate with an Equivalent l'hickness

C. 1 Cross-Sectional slisc of Uule l'hickness Through Cavity W1thout Side Stays

C.2 Free Body Diagrams of Spans A and B in Cavity Without Side Stays (Axial End Reactions Not Shown)

D. 1 Cross-Sectional Slice of Unit Thickness Through

Cavity with Side Staye

D. 2 Free Body Diagrams of Spans $a, b$, and $c$ for Not Shown)

D.3 Free Body Diagram of a Span Labeled in General Terms 


\title{
SIMPLIFIED CALCULATIONS FOR SMALL DEFLECTIONS IN WALLS OF RADIO FREQUENCY CAVITIES
}

\begin{abstract}
The elastic behavior of two types of radio frequency cavities considered for a separated orbit cyclotron was analyzed to determine whether or not the magnitude and distribution of the deflections in the walls of the cavities caused by atmospheric loading can be predicted and controlled. Expressions were derived for the elastic curves that describe the deflections in the walls, and methods were devised to study the structural parameters; the size, shape, wall thickness, and size and spacing of the stiffeners. Computer programs were written to perform the numerical calculations, and these methods of analysis were applied to different design conditions. It was concluded that flexural rigidities can be made to vary as required to obtain specific deflection patterns, but this principle is difficult to apply to any degree for the conditions and purpose considered.
\end{abstract}

\section{INTRODUCTION}

Several types of radio frequency cavities have been considered for use in a separated orbit cyclotron. Radio frequency cavities produce the electric fields that accelerate ion beams in particle accelerators such as a separated orbit cyclotron. These cavities are vessels that are specially shaped to resonate at a certain radio frequency, and any dimensional deviation from the optimum size and shape of the cavity changes the resonant frequency. The cavities or vessels are evacuated during operation, and dimensional changes may result from atmospheric pressure loading caused -by this evacuation and from heating caused by radio frequency currents. Maximum efficiancy is achieved when the cavity, by virtue of its size and shape, resonates with the precisely controlled frequency of the radio frequency input. A shift in resonant frequency resulting from a dimensional deviation is a function of the distribution, magnitude, and direction of the deviation, and frequency shifts must be corrected with tuners. 
This requires an increase in power input and results in a decrease in efficiency. It is theretore important to be able to predicl and cuiliul both the magnitude and distribution of the deflections in the walls of the cavities that are caused by atmospheric loading.

of the several types of radio frequency cavities considered for a separated orbit cyclotron, two were studied in detail with respect to their elastic behavior. These two are the single-gap cavity with either tapered sides, as shown in Fig. 1, or parallel sides, as shown in Fig. 2, for the energy region above $100 \mathrm{Mev}$ and the double-gap (coaxial) cavity, as shown in Fig. 3, for the energy region below $100 \mathrm{Mev}$. In analyzing their elastic behavior, the essential difference between these tio types of cavities is that the single-gap cavity has side stays and the doublegap cavity does not. The side stays of the single-gap cavity are the result of economic considerations and space requirements, whereas the size of the cavity and the space available in the accelerator permit the walls of the double-gap cavity to be designed without stays.

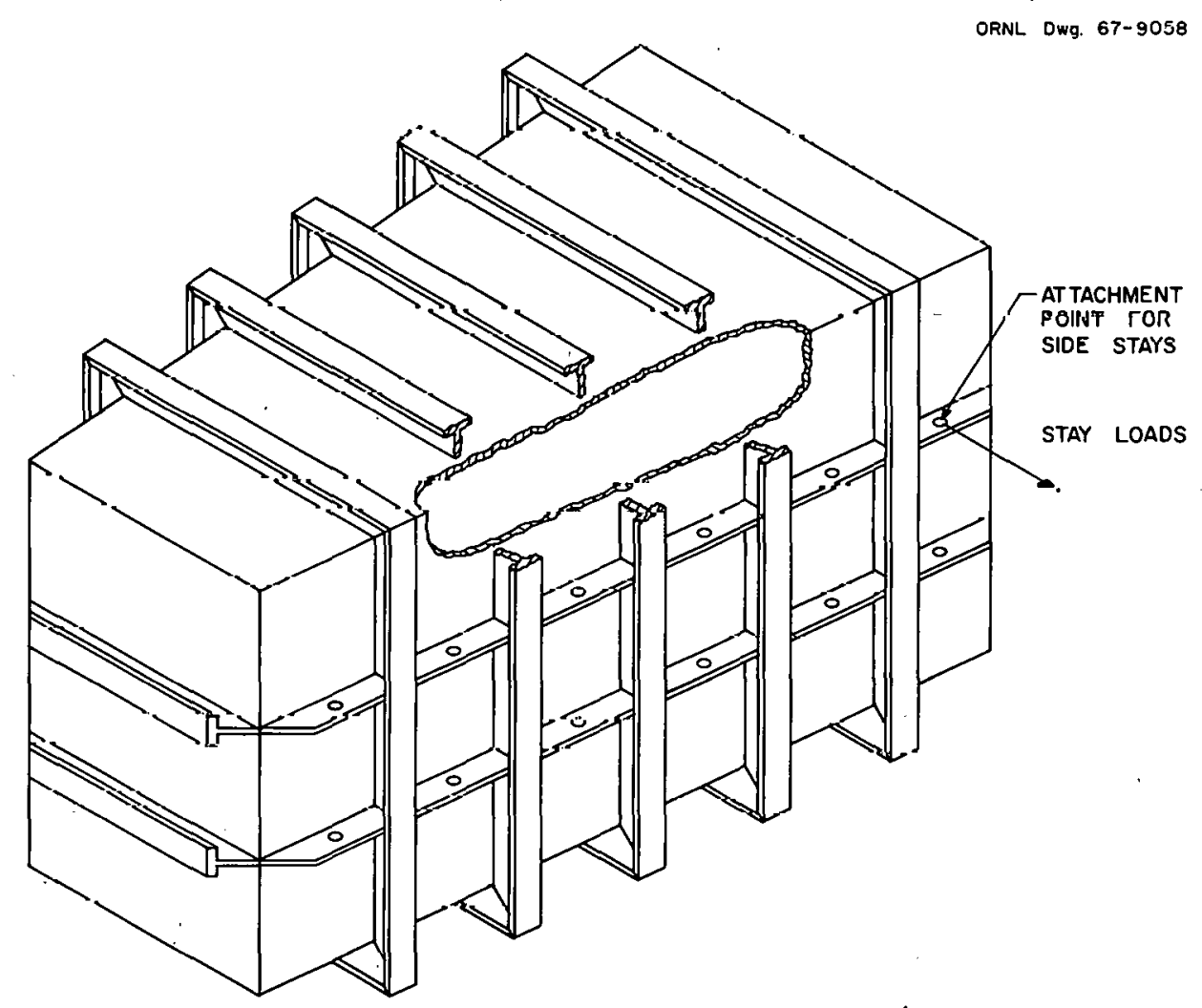

Fig. 1. Single-Gap Cavity With Flat Tapered Sides, Flat Parallel Top and Bottom, Flat Ends, and Side Stays for the Energy Region Above $100 \mathrm{Mev}$. 


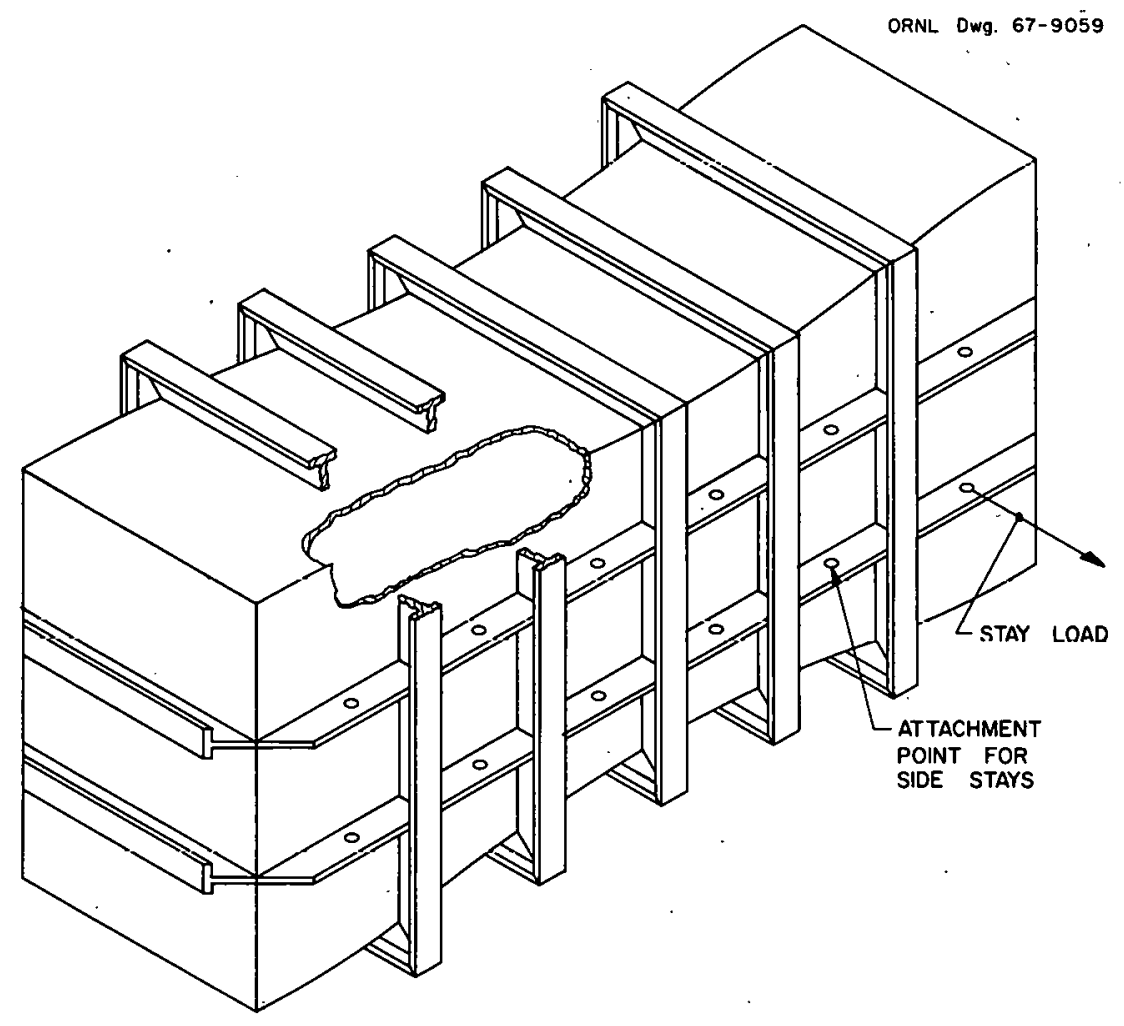

Fig. 2. Single-Gap Cavity With Flat Parallel Sides, Shaped Top and Bottom, Flat Ends, and Side Stays for the Energy Region Above $100 \mathrm{Mev}$.

ORNL OWg. 67-9060

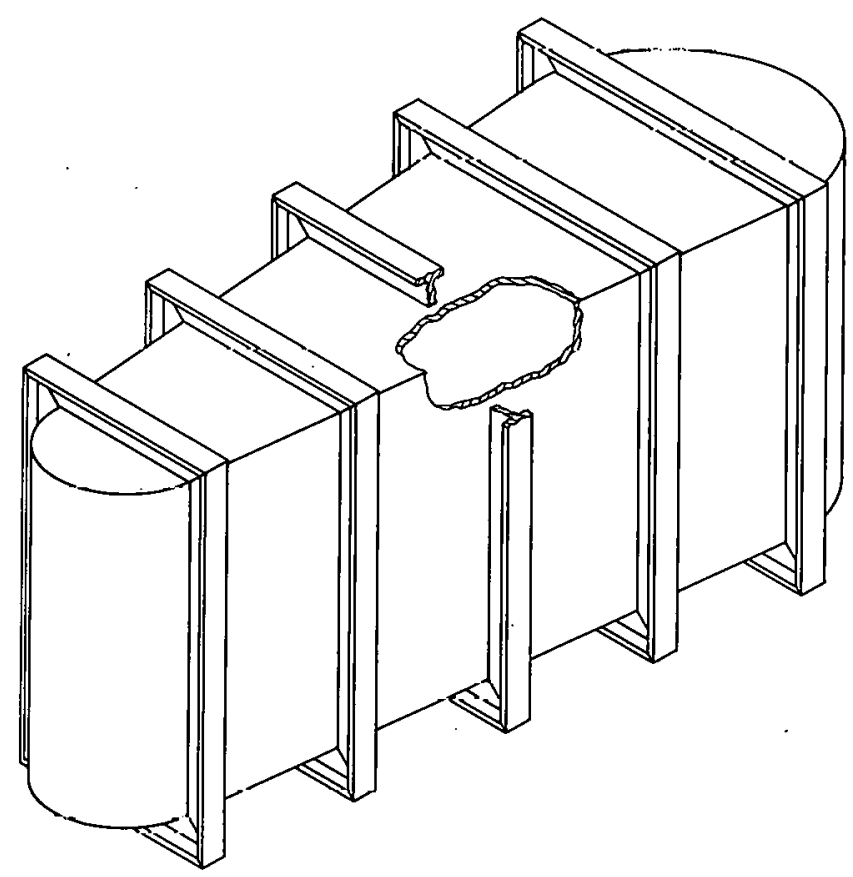

Fig. 3. Double-Gap Cavity With Flat Tapered Sides, Flat Parallel Top and Bottom, Cylindrical Ends, and No Side Stays for the Energy Region Below $100 \mathrm{Mev}$. 
The methods of mathematical analysis of the elastic behavior of the two types of radio frequency cavities studied were developed, and these are discussed in Chapter 2. Equations for the elastic curves, bending moments, and end slopes for both types of cavity were derived. A multiparameter study of plate thickness, stiffener size, and stiffener spacing had to be made to choose the combination desired for the cavity. This choice is based upon permissible deflections, moments, and stresses within the plate panels of the cavity walls, and two computer programs were written to aid in the selection of the desired combination. One program was designed to compute the characteristics of the composite structure as a function of stiffener size and spacing and plate thickness. The second program was designed to study deflections, moments, and stresses of flat plates.

Four numerical examples of different approaches to the application of these methods of mathematical analysis to the design of radio frequency cavities are presented in Chapter 3, and the conclusions drawn from these examples are given in Chapter 4. 


\section{METHODS OF MATHEMATICAL ANALYSIS}

Two types of radio frequency cavities were studied in detail with respect to their elastic behavior. These two types are the single-gap cavity with either tapered or parallel sides for the energy region above $100 \mathrm{Mev}$ and the double-gap (coaxial) cavity for the energy region below $100 \mathrm{Mev}$. A thorough and complete analysis of the elastic behavior of the walls of these cavities would involve very complicated and tedious mathematics. Therefore, assumptions were made to simplify the mathematics. In spite of this, the simplified analysis appears to be adequate and the numerical evaluations are sufficiently accurate to be used for design purposes.

\section{Assumptions}

The type construction to be used for the walls of the cavities was assumed to be as shown in Fig. 4. Both the single- and double-gap cavities were assumed to be made of copper-lined carbon-steel plate, and the numerical calculations were based on the use of 0.1-in.-thick OFHC copper on 0.40-in.-thick carbon steel. However, the prototype cavity

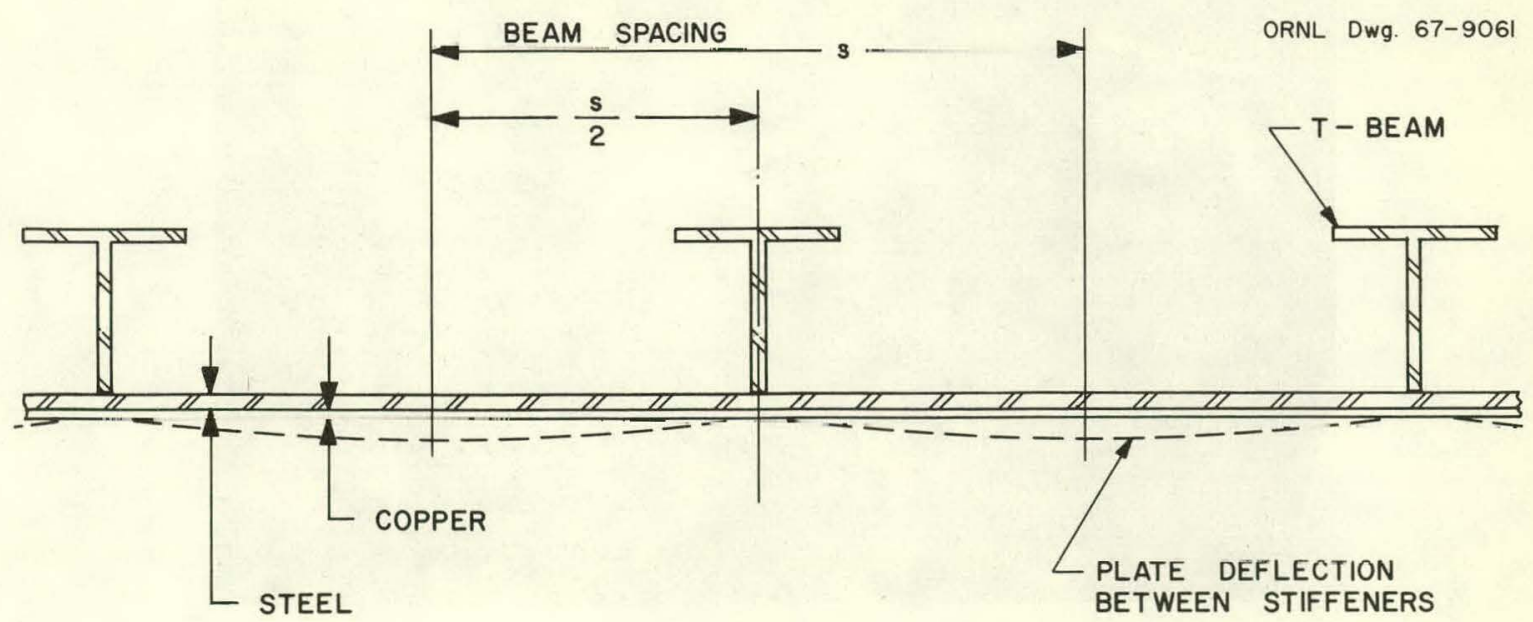

Fig. 4. Type Construction Assumed for Cavity Walls. 
for a 50-Mev separated orbit cyclotron shown in Figs. 5 and 6 was fabricated from 0.05-in.-thick copper on 0.45-in.-thick steel. The walls of both the single- and double-gap cavities have external stiffening members assumed to be in the form of T-beams, as shown in Fig. 4. The flexural rigidity of a composite structure made by welding T-beam stiffeners on steel plate was assumed to be equivalent to that of a solid steel plate with an equal second moment of area. The equation for the equivalent thickness of this solid steel plate is derived in Appendix A.

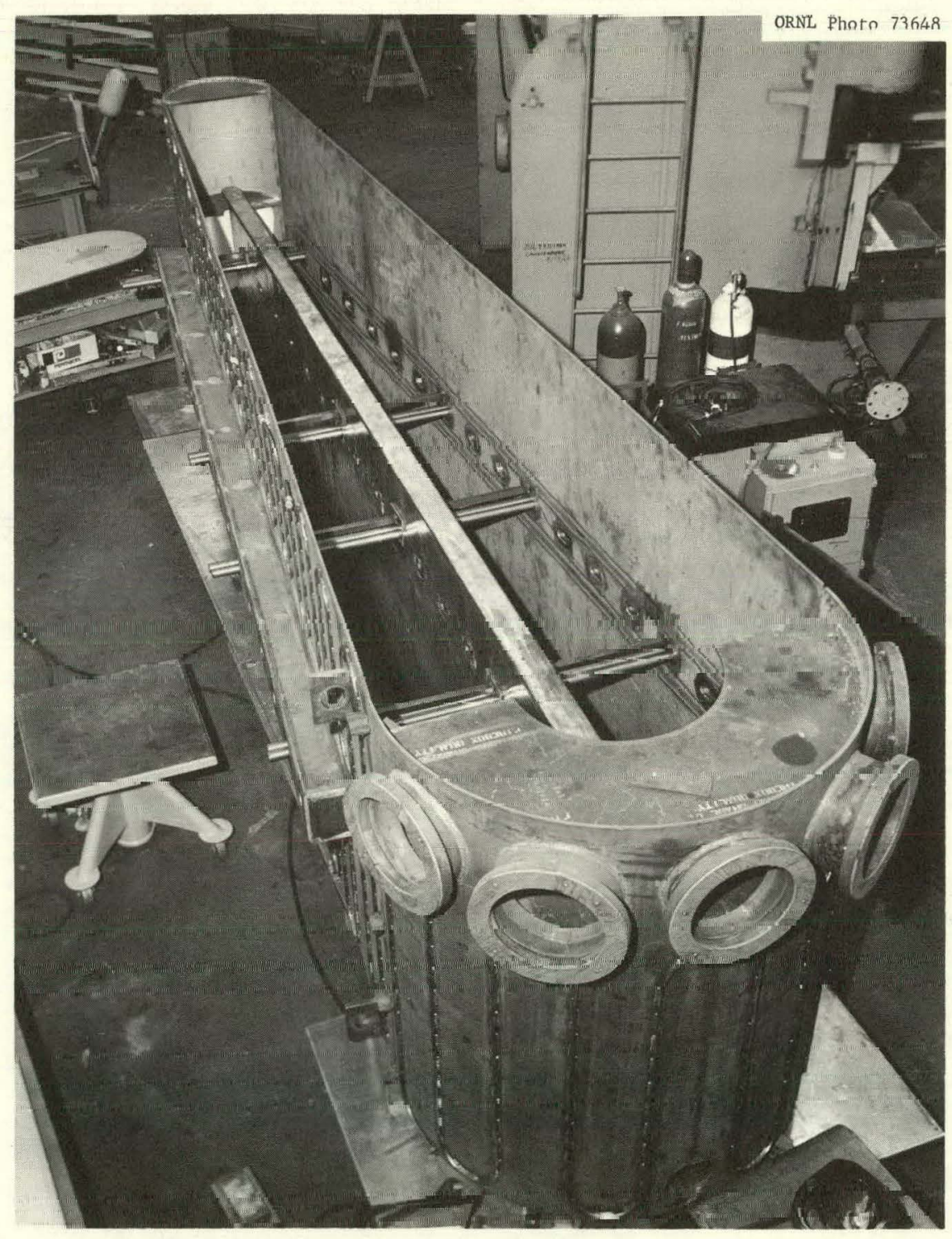

Fig. 5. Prototype of Radio Frequency Cavity for a 50-Mev Separated Orbit Cyclotron During Construction. 


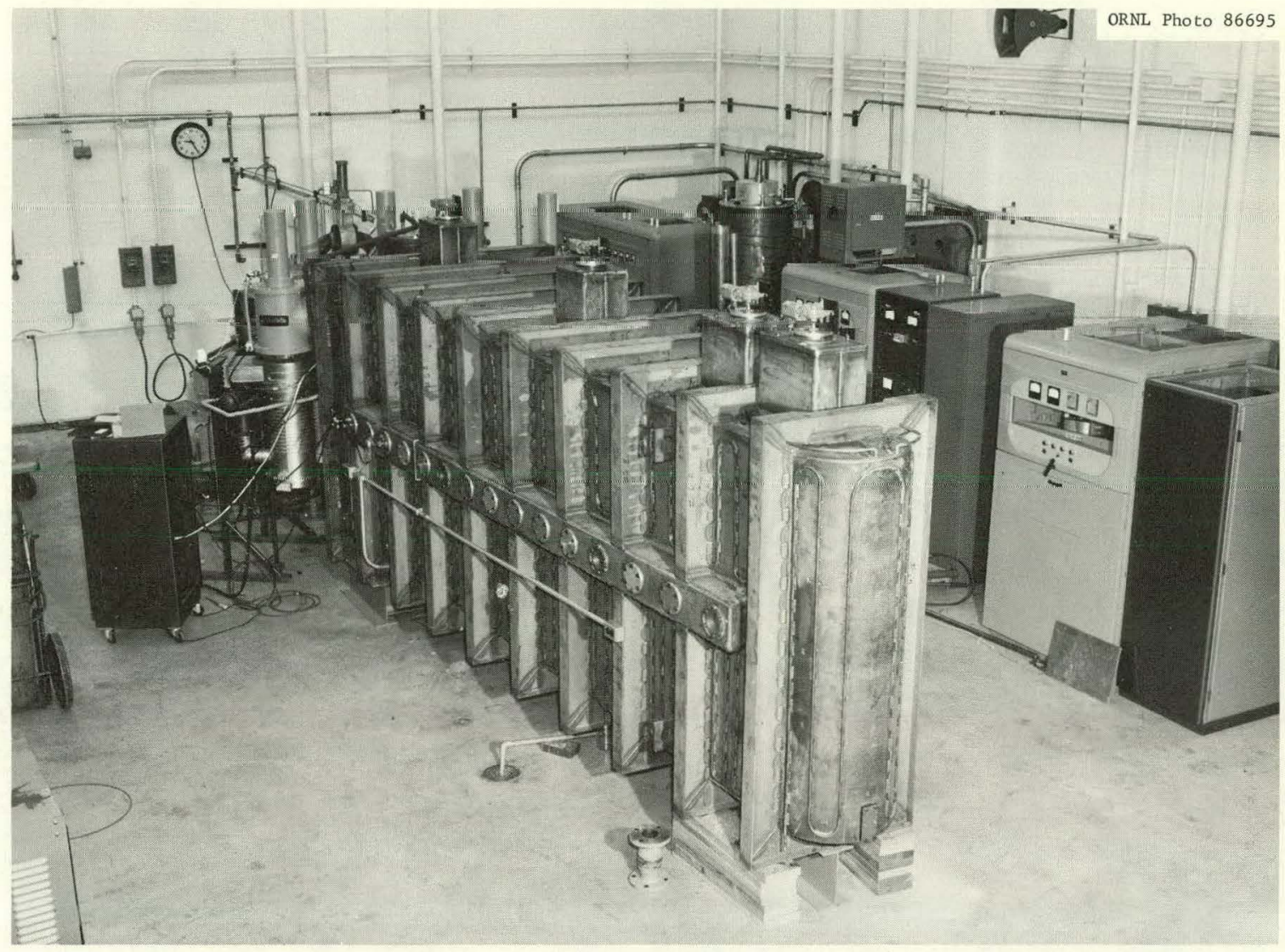

Fig. 6. Prototype of Radio Frequency Cavity for a 50-Mev Separated Orbit Cyclotron After Addition of Stiffeners.

The single-gap cavity was assumed to have side stays, while the double-gap cavity was assumed to have no side stays. It was also assumed that there are no openings in the walls of the cavities. The effects of the ends of the cavities were neglected. The ettect of local deflections in the panels of flat plate between the stiffeners was neglected in the derivation of the elastic curve for the composite structure. Local panel deflections were considered separately, and in calculating them, the copper-clad steel plate was regarded as a solid steel plate of equivalent thickness. The equation for the equivalent thickness of a solid steel plate is derived in Appendix B.

The effects of adjacent steel panels upon each other caused by gradual changes in the shape of the cavity were neglected. This assumption will hold for the single-gap rectangular cavity with shaped top and bottom and parallel sides if the change in shape occurs gradually. It 
will also hold for the single-gap cavity with flat tapered sides and the double-gap cavity with flat tapered sides if the angle of taper between the sides is small.

\section{Equations Derived for Cavity Without Side Stays}

The expressions for the elastic curves that describe the deflections in the walls of the double-gap cavity and the expressions for the bending moments and end slopes are derived in Appendix C. For these derivations, a cross-sectional slice of unit thickness is taken through the cavity without side stays, and the height of this slice is denoted by the letter $a$ and the width by the letter $b$. The desired expressions are derived for two cases: (1) the case where the flpxural rigidity of the cideo, EI, is different from the flexural rigidity of the top and bottom, $\mathrm{EI}_{\mathrm{b}}$, and (2) the case where the flexural rigidity of the sides is the same as that of the top and bottom.

Case 1

In the first case, $\mathrm{EI}_{\mathrm{a}}+\mathrm{EI}_{\mathrm{b}}$, the elastic curve (deflection) of the sides, span a,

$$
\mathrm{y}_{\mathrm{a}}=\frac{1}{\mathrm{EI}}\left(\frac{\mathrm{M} \mathrm{x}^{2}}{-2}+\frac{\mathrm{wax}^{3}}{12}-\frac{\mathrm{wx}^{4}}{24}\right)-\theta_{\mathrm{A}} \mathrm{x} .
$$

The deflection of span b across the top and bottom,

$$
y_{b}=\frac{1}{E I_{b}}\left(\frac{M x^{2}}{2}+\frac{w b x^{3}}{12}-\frac{w x^{4}}{24}\right)+\theta_{A} x
$$

The moment,

$$
M_{1}=\frac{w}{12}\left(\frac{a^{3} I_{b}+b^{3} I_{a}}{a I_{b}+b I_{a}}\right) .
$$

The end slope,

$$
\theta_{A}=\frac{w a b}{24 E} \quad\left(\frac{a^{2}-b^{2}}{a I_{b}+b I_{a}}\right) \text {. }
$$




\section{Case 2}

In the second case, $E I_{a}=E I_{b}=E I$, the moment,

$$
M_{1}=\frac{w}{12}\left(a^{2}-a b+b^{2}\right)
$$

and the end slope,

$$
\theta_{\mathrm{A}}=\frac{\mathrm{wab}(\mathrm{a}-\mathrm{b})}{24 \mathrm{EI}}
$$

The deflection of the sides, span a,

$$
y_{a}=\frac{w x}{24 E I}\left[-\left(a^{2}-a b+b^{2}\right) x+2 a x^{2}-x^{3}-a b(a-b)\right],
$$

and the deflection of the top and bottom, span $b$,

$$
y_{b}=\frac{w x}{24 E I}\left[-\left(a^{2}-a b+b^{2}\right) x+2 b x^{2}-x^{3}+a b(a-b)\right] \text {. }
$$

The maximum deflection of span a (the sides) occurs at $\mathrm{x}=\mathrm{a} / 2$, and

$$
y_{a \max }=-\frac{w a^{2}}{384 E I}\left(a^{2}+4 a b-4 b^{2}\right)
$$

The maximum deflection of span $b$ (the top and bottom) occurs at $\mathrm{x}=\mathrm{b} / 2$, and

$$
y_{b \max }=-\frac{w b^{2}}{384 E I}(2 a-b)(6 a-5 b) .
$$

\section{Equations Derived for Cavities With Side Stays}

The expressions for the elastic curves that describe the deflections in the walls of the single-gap cavities and the expressions for the bending moments. and end slopes are derived in Appendix D. For these derivations, a cross-sectional slice of unit thickness is taken through the cavity with side stays, and the overall height of the section, $l$, is bruken by two stays. The distance between the stays is denoted by the letter a, the distance from a stay to either the top or bottom of the cavity is denoted by the letter $b$, and the width of the cross-sectional slice by the letter c. The desired expressions are derived for three cases: 
(1) the case where spans $a, b$, and $c$ and the flexural rigidities $E I_{a}$, $E I_{b}$, and $E I_{c}$ may be different from each other, (2) the case where span $a=s p a n b$ but spans $a$ and $b$ may be different from span $c$ and the plane moments of inertia $I_{a}=I_{b}$ but $I_{a}$ and $I_{b}$ may be different from $I_{c}$, and (3) the case where $I_{a}=I_{b}=I_{c}=I$ and $a=b$ but $a$ and $b$ may be different from $c$.

\section{Case 1}

In the firot case, $I_{a} \neq I_{b} \neq I_{c}$ and $a \neq b \neq c$, the elastic curve (deflection) of span a,

$$
y_{a}=\frac{1}{E_{a}}\left(-\frac{w x^{4}}{24}+\frac{w a x^{3}}{12}-\frac{M x^{2}}{2}\right)+\theta_{G} x
$$

the deflection of span $b$,

$$
\mathrm{y}_{\mathrm{b}}=\frac{1}{\mathrm{EI} \mathrm{I}_{\mathrm{b}}}\left(-\frac{\mathrm{wx}}{24}+\frac{\mathrm{R} \cdot \mathrm{x}^{2}}{6}-\frac{\mathrm{M} \mathrm{x}^{2}}{2}\right)-\theta_{\mathrm{G}} \mathrm{x}
$$

and the deflection of span c,

$$
y_{c}=\frac{1}{E I_{c}}\left|-\frac{w x^{4}}{24}+\frac{w c x^{3}}{12}-\frac{M x^{2}}{2}\right|+\theta_{A} x .
$$

The reaction,

$$
R_{3}=\frac{\left.w\left(a^{3} I_{b}-b^{3} I_{a}\right)\left(b I_{c}+c i_{b}\right)-\left(a I_{b}+b I_{a}\right)\left(c^{3} I_{b}-6 b{ }^{3} c I_{b}-3 b^{3} I_{c}\right)\right]}{4 b\left[\left(2 b I_{c}+3 c I_{b}\right)\left(a I_{b}+b I_{a}\right)-b I_{a}\left(b I_{c}+c I_{b}\right)\right.}
$$

The moment

$$
M_{3}=\frac{w\left(a^{3} I_{b}-b^{3} I_{a}\right)+4 b^{2} I_{a} R_{3}}{12\left(a I_{b}+b I_{3}\right)} .
$$

The end slopes

$$
\theta_{A}=\frac{8 b^{2} R_{3}-12 b M-3 w b^{3}}{24 E I_{b}}
$$

and

$$
\theta_{G}=\frac{12 a M_{G}-w^{3}}{24 E I a} .
$$


The moment

$$
M_{I}=\frac{24 E I_{c} \theta_{A}+w c^{3}}{12 c}
$$

The stay load,

$$
P=R_{3}+\frac{w a}{2}
$$

For span a, the mid-span deflection that occurs at $x=a / 2$,

$$
\left.y_{a \text { mid-span }}=\frac{1}{E I_{a}} \mid \frac{\mathrm{wa}^{4}}{128}-\frac{\mathrm{a}^{2} \mathrm{M}_{3}}{8}\right)+\frac{\mathrm{a}{ }_{\mathrm{G}}}{2} \text {. }
$$

For span $b$, the mid-span deflection that occurs at $x=b / 2$,

$$
\mathrm{y}_{\mathrm{b} \text { mid-span }}=\frac{1}{E I_{b}}\left(-\frac{\mathrm{wb}^{4}}{384}+\frac{\mathrm{b}^{3} \mathrm{R}_{3}}{48}-\frac{\mathrm{b}^{3} \mathrm{M}_{3}}{8}\right)-\frac{\mathrm{b} \theta_{G}}{2} .
$$

For span c, the mid-span deflection that occurs at $x=c / 2$,

$$
\left.y_{c \text { mid-span }}=\frac{1}{E I_{c}} \mid \frac{w c^{4}}{128}-\frac{M_{l} c^{2}}{8}\right)+\frac{c \theta A}{2} .
$$

All of the expressions for this first case are also applicable in the second and third cases. However, the expressions for the deflections at mid-span and the elastic curves are not simpler in cases 2 and 3 than they are in case 1, and they therefore will not be repeated for the last two cases.

\section{Case 2}

In the second case, $a=b$ and $I_{a}=I_{b}$, the reaction

$$
R_{3}=\frac{w\left(3 a^{3} I_{c}+6 a^{2} c I_{a}-c^{3} I_{a}\right)}{2 a\left(3 a I_{c}+5 c I_{a}\right)}
$$

The moment

$$
\mathrm{M}_{3}=\frac{\mathrm{a}}{6} \mathrm{R}_{3} .
$$


The end slope,

$$
A_{A}=\frac{a^{2}}{8 E I_{a}}\left(2 R_{3}-w a\right)
$$

and

$$
\theta_{G}=\frac{a^{2}}{24 E I_{a}}\left(2 R_{3}-w a\right)=\frac{\theta_{A}}{3} \text {. }
$$

The moment

$$
M_{I}=\frac{24 E I_{c}{ }^{\theta} A+w c^{3}}{12 c} .
$$

The stay load

$$
P=R_{R}+\frac{w a}{2}
$$

\section{Case 3}

In the third case, $a=b$ and $I_{a}=I_{b}=I_{c}=I$, the reaction,

$$
R_{3}=\frac{w\left(3 a^{3}+6 a^{2} c-c^{3}\right)}{2 a(3 a+5 c)}
$$

The moment

$$
M_{3}=\frac{a}{6} R_{3}=\frac{w\left(3 a^{3}+6 a^{2} c-c^{3}\right)}{12(3 a+5 c)} .
$$

The end slopes

$$
\theta_{A}=\frac{a^{2}}{8 E I}\left(2 R_{3}-w a\right)=\frac{a c w\left(a^{2}-c^{2}\right)}{8 E I(3 a+5 c)}
$$

and

$$
\theta_{G}=\frac{a^{2}}{24 E I}\left(2 R_{3}-w a\right)=\frac{\theta_{A}}{3}=\frac{a c w\left(a^{2}-c^{2}\right)}{24 E I(3 a+5 c)} .
$$

The moment

$$
M_{1}=\frac{24 E I \theta_{A}+w c^{3}}{12 c}=\frac{w\left(3 a^{3}+5 c^{3}\right)}{12(3 a+5 c)} .
$$

The stay load

$$
\left.P .=R_{3}+\frac{w a}{2}=\frac{w}{2}: \frac{6 a^{3}+11 a^{2} c-c^{3}}{3 a+5 c}\right)
$$


Panel Deflections, Moments, and Stresses

In a composite wall structure, it is necessary to consider the deflections and stresses within the flat plate panels between stiffeners as well as the deflections of the whole composite wall. The problem boils down to one of choosing a suitable combination of stiffener size and spacing and plate thickness that will satisfy the criteria for both the composite wall and the plate panels between the stiffeners. While it must meet specific design criteria, the choice is usually also influenced by economics and local situation factors such as the material already on hand.

With deflection criteria established, values for the flexural rigidity, EI, of the composite walls may be determined from expressions that are derived in Appendices $C$ and $D$. Values for the second moment of area, I, follow when the materials of construction are known or selected. With the value of the second moment of area known, a multi-parameter study of plate thickness and stiffener size and spacing must be made with the choice of the combination based upon the permissible deflections, moments, and stresses within the plate panels. After the combination is chosen on this basis, it must be confirmed by checking the stresses in the composite structure.

Two computer programs were written to aid in the selection of a suitable combination of plate thickness and stiffener size and spacing. One of the programs, called TBEAM, is used to solve the equations of Appendix A. The characteristics of the composite structure are computed as a function of the T-beam stiffener size and spacing and the plate thickness. The properties of 77 "standard" T-beams are read into the computer memory. These properties include weight $(1 \mathrm{~b} / \mathrm{ft})$, area (in. ${ }^{2}$ ), depth of beam (in.), width of flange (in.), thickness of flange (in.), thickness of stem (in.), moment of inertia (in. ${ }^{4}$ ), and a value representing the location of the centroidal axis (in.), as found in steel handbooks. Several spacings for stiffeners $(12,15,18, \ldots$, and 39 in.) are also generated and stored, and a number of arbritrary plate thicknesses are also read into the computer, such as $0.345,0.375$, 
$0.4375,0.461$, and 0.500 in. The computer output consists of a listing of some of the characteristics of the composite structure as a function of the input parameters. The important output items include (1) the total amount of inertia (in. ${ }^{4}$ ) of the composite structure, (2) a unitized moment of inertia (in. ${ }^{4 / i n .)}$ obtained by dividing the total moment of inertia by the spacing (in.), (3) a unitized weight (lb/ft per in.) obtained by dividing the weight per foot of length of the composite structure by the spacing in in., (4) a relative efficiency term (in. ${ }^{4} /$ 1b per $\mathrm{ft}$ ) obtained by dividing Item 2 above by Item 3, and (5) a value for the centroidal axis (in.) of the composite structurc. $\Lambda$ listing of the properties of the 'l'-beam is also included as computer output data. Regardless of how determined, if the required unitized moment of inertia is known, a combination of stiffener size and spacing and plate thickness can be found to meet the requirements in an approximate manner. Then, if the plate thickness and stiffener spacing are known, the most efficient $T$-beam of all possible ones can be determined. The characteristics of this $\mathrm{T}$-beam can then be examined to determine its suitability from the standpoint of depth and stress.

A second computer program used in conjunction with TBEAM, called PANEL, was written to aid in the parameter study of the deflectinns, moments, and stresses of flat plates. The input parameters are (1) plate. thickness (in.), (2) panel length (in.), and (3) panel width (in.). The computer output lists the values for $\alpha$ and $\beta$, the maximum deflection of the panel, $y_{x} \equiv n, y=n$, where the coordinate axis is as shown in Fig. 7, the moment, $\left(M_{x}\right)_{x}=s / 2, y=0$, and the maximum stress, $s_{\max }$. When the requirements of the composite structure and the panels between sclffeners are known in terms of (1) the required moment of inertia of the composite structure based on permissible deflertinns, (2) the limiting stresses in the composite structure, and (3) the permissible moments, stresses and deflections in the plate panels, a suitable and perhaps the most economical combination of stiffener size and spacing and plate thickness can be found from the output data of the computer programs TBEAM and PANEL. 


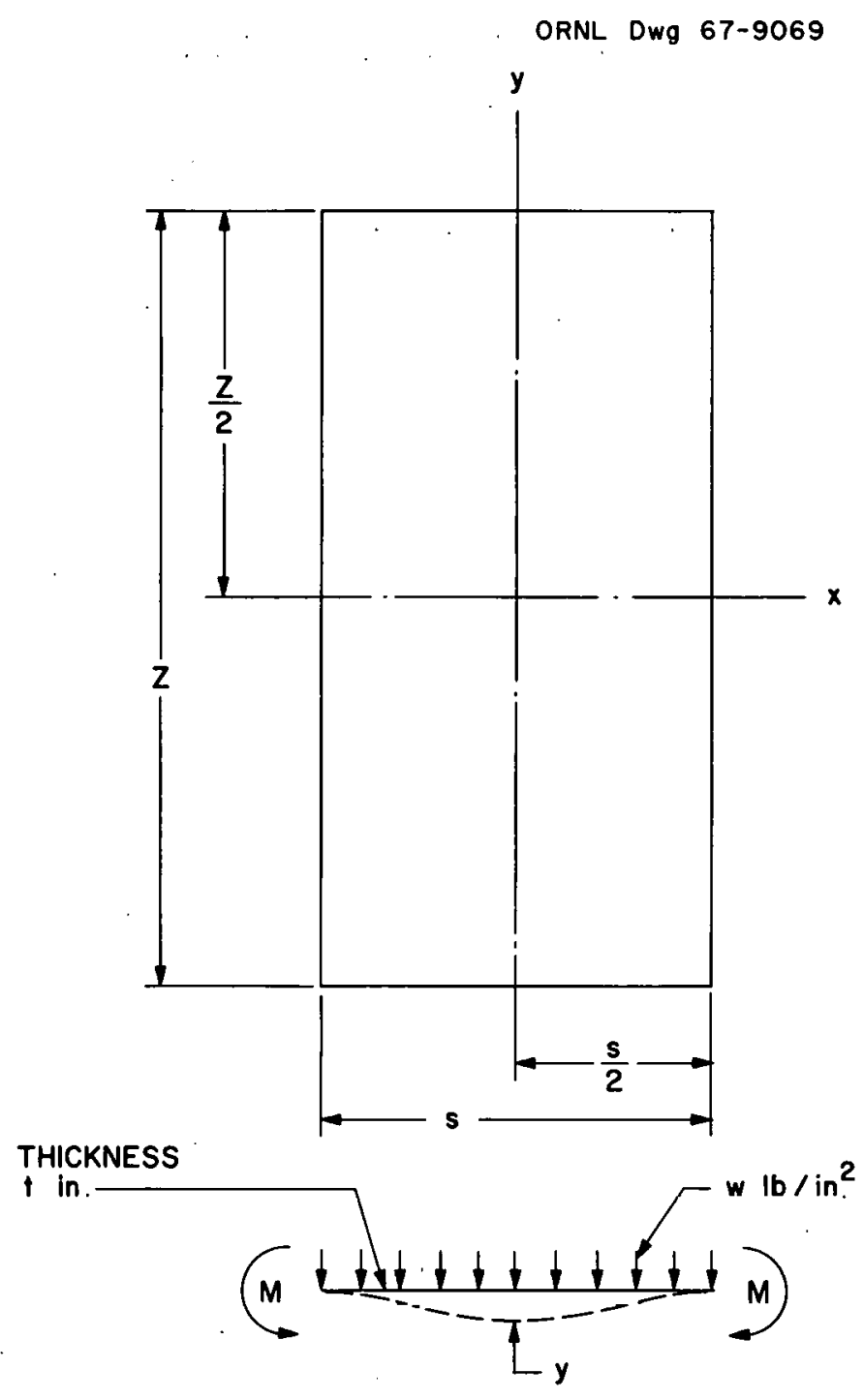

Fig. 7. Coordinate Axis for Maximum Deflection of Panel Determined by the Computer Program PANEL.

The particular plate used to construct the prototype double-gap cavity for a 50 -Mev separated orbit cyclotron was chosen because it was available from surplus stock. Once the thickness of the plate is chusell, the slze of the T-beam stiffener will depend upon its spacing. Thus, in the case of the prototype, the problem became one of determining the spacing of the stiffencrs, which is the same as the width of the panels. In the wall structure of the cavities, the panels are rectangular and assumed to be fixed (clamped) on all four edges, but 
the panels will deflect somewhat between stiffeners, as indicated in Figs. 4 and 7. Based on deflections or stresses, or both, the following five expressions ${ }^{1}$ may be used to choose the widths of the panels. The expressions for $\alpha$ and $\beta$ are given in equation form to facilitate their use in FORTRAN for computer programming.

$$
\begin{aligned}
& \mathrm{y}_{\mathrm{x}=0, \mathrm{y}=0}=\alpha \frac{\mathrm{ws^{4 }}}{\mathrm{Et^{3 }}} \mathrm{in} \text {. } \\
& \alpha=\frac{0.0284}{1+1.056\left(\frac{s}{z}\right)^{5}} \\
& \left(M_{x}\right)_{x=s / 2, y=0}=\beta w s^{2} \text { in. }-1 b / i n . \\
& \beta=\frac{0.0833}{1+0.623 / \frac{s^{6}}{2}} \\
& S_{\max }=\frac{M}{2}=\frac{6 M}{t^{2}} \quad 1 b / \text { in. }{ }^{2}
\end{aligned}
$$

\begin{tabular}{|c|c|c|c|}
\hline $\begin{array}{l}\text { Term in } \\
\text { Table I }\end{array}$ & Definition & $\begin{array}{l}\text { Term in } \\
\text { Equation }\end{array}$ & Unit \\
\hline $\mathrm{Z}$ & Pane 1 length & $z$ & in. \\
\hline $\mathrm{S}$ & Pane 1 width & s & in. \\
\hline $\mathrm{A}$ & alpha & $\alpha$ & dimensionless \\
\hline B & beta & 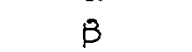 & diutens iuñless \\
\hline $\mathrm{Y}$ & Deflection & $y$ & in. \\
\hline $\mathrm{XM}$ & Moment & $M_{x}$ & in. $-1 b /$ in. \\
\hline $\mathrm{ST}$ & Maximum stress & $S_{\max }$ & psi \\
\hline
\end{tabular}

Computer program PANEL output data for values of deflections, $\mathrm{y}_{\mathrm{x}}=0, \mathrm{y}=0$, mómentes, $\left(M_{\mathrm{x}}\right)^{\mathrm{x}}=\mathrm{s} / 2, \mathrm{y}=0$, maximum stress, $s_{\max }, \alpha$, and $\beta$, are given in Table 1 for selected values of panel lengths, $z$, and panel widths, s. The format for Table 1 is as defined below.

${ }^{1}$ R. J. Roark, p. 205 in Formulas for Stress and Strain, 3rd ed., McGraw-Hill Book Company, Inc., 1954. 
Table 1. PANEL Computer Program Cutput Data for Panel Deflections, Moments, and Stresses for Selected Valces of Panel Lengths and Widths

\begin{tabular}{|c|c|c|c|c|c|c|c|c|}
\hline $\mathrm{Z}=$ & 56.0 & & & & & & & \\
\hline$S=$ & $\div 5.0$ & 18.0 & 21.0 & 24.0 & 27.0 & 30.0 & 33.0 & 36.0 \\
\hline$A=$ & 0.02803 & .02749 & .02651 & .02493 & .02271 & .01994 & .01687 & .01381 \\
\hline $\mathrm{B}=$ & 0.03303 & .08250 & .08130 & .07898 & .07499 & .06892 & .06082 & .05132 \\
\hline $\mathrm{Y}=$ & 0.00734 & .01493 & .02667 & .04280 & .06244 & .08356 & .10351 & .12004 \\
\hline$X M=$ & 274.6 & 392.9 & 527.1 & 668.7 & 803.6 & 911.8 & 973.6 & 977.8 \\
\hline$S T=$ & 7753.2 & 11093.0 & 14880.5 & 18880.2 & 22686.7 & 25742.9 & 27487.8 & 27605.7 \\
\hline$z=$ & 42.0 & & & . & & & & \\
\hline$S=$ & 15.0 & 18.0 & 21.0 & 24.0 & 27.0 & 30.0 & 33.0 & 36.0 \\
\hline$A=$ & .02823 & .02797 & .02749 & .02668 & .02545 & .02374 & .02158 & .01908 \\
\hline$B=$ & .08319 & .08298 & .08250 & .08153 & .07979 & .07693 & .07265 & .06680 \\
\hline $\mathrm{Y}=$ & .30739 & .01519 & .02766 & .04580 & .06998 & .09949 & .13239 & .16580 \\
\hline$X M=$ & 275.2 & 395.2 & 534.8 & 690.3 & 855.1 & 1017.8 & 1163.0 & 1272.6 \\
\hline $\mathrm{ST}=$ & 7768.4 & 11157.9 & 15098.8 & 19490.1 & 24140.7 & 28736.2 & 32834.9 & 35927.6 \\
\hline$Z=$ & 48.0 & & & & & & & \\
\hline$S=$ & 15.0 & 18.0 & 21.0 & 24.0 & 27.0 & 30.0 & 33.0 & 36.0 \\
\hline$A=$ & .02831 & .02818 & .02793 & .02749 & .02681 & .02580 & .02444 & .02271 \\
\hline $\mathrm{B}=$ & .08325 & .08316 & .08294 & .08250 & .08169 & .08032 & .07816 & .07499 \\
\hline $\mathrm{Y}=$ & .00742 & .01531 & .02810 & .04719 & .07371 & .10831 & .14994 & .19735 \\
\hline $\mathrm{XM}=$ & 275.4 & 396.1 & 537.7 & 698.5 & 875.4 & 1062.6 & 1251.2 & 1428.6 \\
\hline$S T=$ & 7774.0 & 11181.6 & 15179.5 & 19720.9 & 24714.5 & 29999.9 & 35324.0 & 40332.0 \\
\hline$Z=$ & 54.0 & & & & & & & \\
\hline $\mathrm{S}=$ & 15.0 & 18.0 & 21.0 & 24.0 & 27.0 & 30.0 & 33.0 & 36.0 \\
\hline$A=$ & .02835 & .02828 & .02814 & .02789 & .02749 & .02690 & .02605 & .02493 \\
\hline$B=$ & .08328 & .08323 & .08312 & .08290 & .08250 & .08180 & .08068 & .07898 \\
\hline $\mathrm{Y}=$ & .00743 & .01536 & .02831 & .04787 & .07559 & .11272 & .15987 & .21667 \\
\hline $\mathrm{XM}=$ & 275.4 & 396.4 & 538.8 & 701.9 & 884.1 & 1082.2 & 1291.6 & 1504.7 \\
\hline $\mathrm{ST}=$ & 7776.2 & 11191.4 & 15213.0 & 19817.7 & 24959.3 & 30554.2 & 36464.5 & 42480.6 \\
\hline
\end{tabular}


The computer calculations for the values given in Table 1 are based on a panel plate thickness, $t$, of 0.461 in., a uvilulus of elasticity, $E$, of 29,000,000 psi, and an atmospheric pressure load, w, of 14.7 psi. The beam spacing on the prototype cavity is $21.35 \mathrm{in.}$, and the approximate maximum deflections and stresses to be expected in the various panels of the cavity can be deduced from the values given in the third column of Table 1 . Observe the lengths of the panels, $z$, have little influence on the magnitude of the deflections and stresses for the range of ratios of $s / z$ tabulated. 


\section{NUMERICAL EXAMPLES}

The expressions for the elastic curves, bending moments, and end slopes that are presented in the previous chapter cover a variety of possible design conditions. The form of these expressions suggests that they may be applied in several ways. Four numerical examples of different approaches, of which some have no clear or definite possibilities for design application, are described in the following material. In all of the examples, the atmospheric pressure loading, $w$, is assumed to be $14.7 \mathrm{psi}$ and the modulus of elasticity, E, is assumed to be $29 \mathrm{X}$ $10^{6}$ psi.

\section{Example 1}

For the first example, consider the double-gap cavity without side stays illustrated in Fig. 3. The dimensions of the cavity for this example are shown in Fig. 8.

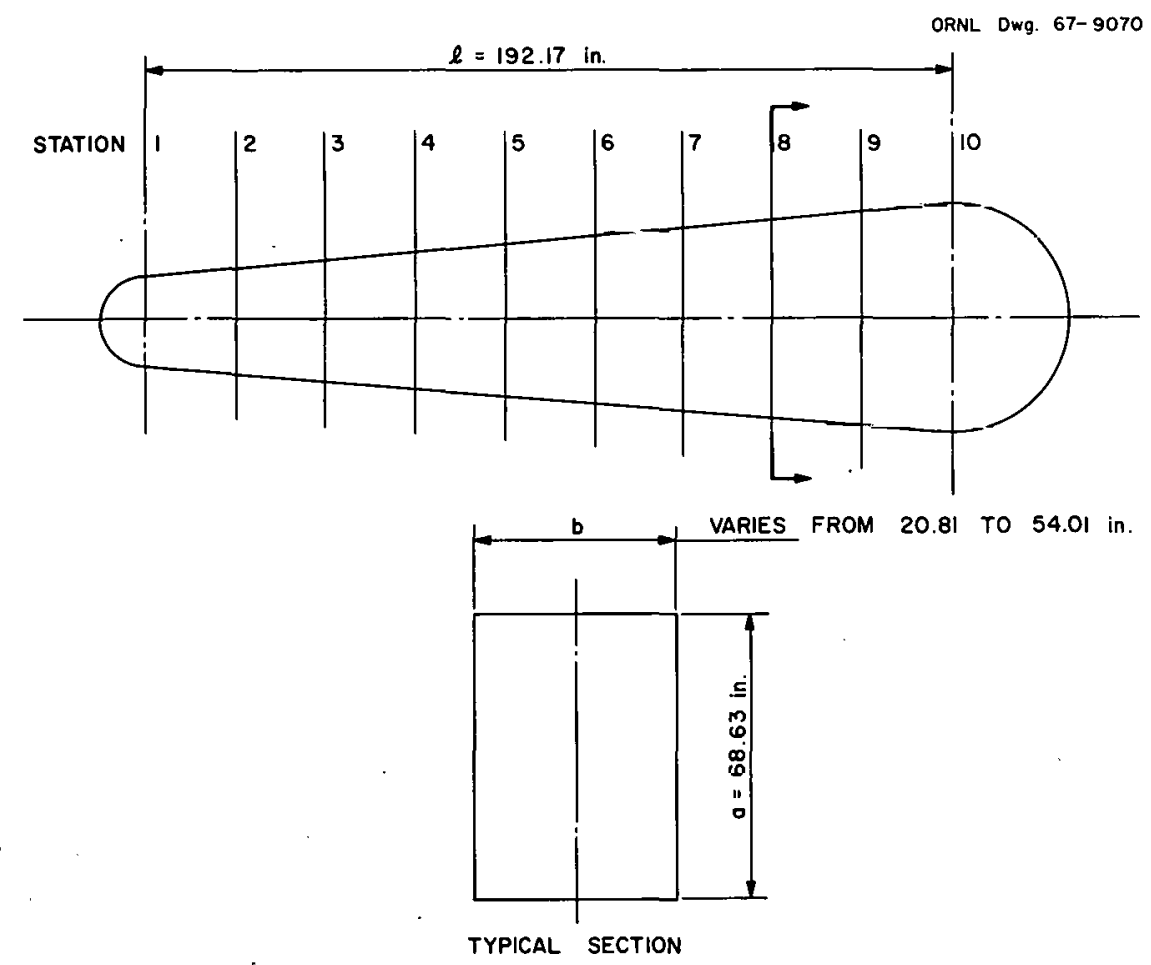

Fig. 8. Dimensions of Double-Gap Cavity Without Side Stays for Numerical Examplc 1. 
In this example, the flexural rigidity, EI, and consequently the second moment of area, I, of the walls arc specified to be constant all over; that is, $I_{a}=I_{b}=I$ at each station. The value of $I$ is to be based upon a specified maximum deflection of side a at the small end of the cavity. Arbitrarily, $y_{a \max }=0.019$ in. at Station 1 , which is at the small end of the cavity.

From Eq. 9, the second moment of area, $I=2.856$ in. ${ }^{4} /$ in. From Eq. C.2, given in Appendix $\mathrm{C}, \mathrm{R}_{2}=504.4 \mathrm{lb}$ per inch of cavity length at each of the 10 stations. Values for $R_{1}$ (Eq. C. 1), $M_{i}$ (Eq. 5), and $\theta_{A}$ (Eq. 6) may be obtained at each of the 10 stations equally spaced along the cavity, and the deflection curves at each of the 10 stations are obtained from Eqs. 1 and 2.

These computations were made by using a simple computer program called COAXCAV-5. The input for the program in this example consists of a deflection condition, $\mathrm{y}_{\mathrm{a} \max }=0.019$ in. at Station 1 , and dimensions to define the size of the cavity. The widths at each station, indicated by the letter b in Fig. 8, are computed, and these widths and the height, a, are divided into 10 equal. spaces for computing the deflection curves. The computer program COAXCAV-5 values for $b, R_{1}, M_{1}, \theta_{A}$, $I$, and $R_{2}$ are given in Table 2. The units for $R_{l}$ and $R_{2}, 1 b / i n$, and $I$, in. ${ }^{4} /$ in., , are the result of taking a 1 -in.-thick (measured in the direction of $\ell$ ) sectional slice of the cavity.

Table 2. Computer Program COAXCAV-5 Output for Reartions, Momento, and End 3lupes for Widths at 10 Stations of the Double-Gap Cavity in Numerical Example 1

\begin{tabular}{ccccc}
\hline Station & $\begin{array}{c}\mathrm{b} \\
\text { (1n.) }\end{array}$ & $\begin{array}{c}\mathrm{R}_{1} \\
(\text { (b/in. })\end{array}$ & $\begin{array}{c}\mathrm{M}_{1} \\
\text { (in. }-1 \mathrm{~b} / \mathrm{in} .)\end{array}$ & $\begin{array}{c}{ }_{\mathrm{A}} \\
\text { (radians) }\end{array}$ \\
\hline 1 & 20.81 & 152.92 & 4550.3 & 0.000505 \\
2 & 24.49 & 180.04 & 4444.8 & 0.000549 \\
3 & 28.18 & 207.15 & 4372.8 & 0.000578 \\
4 & 31.87 & 234.27 & 4334.0 & 0.000594 \\
5 & 35.56 & 261.39 & 4328.7 & 0.000597 \\
6 & 39.25 & 288.51 & 4356.7 & 0.000585 \\
7 & 42.94 & 315.63 & 4418.0 & 0.000560 \\
8 & 46.63 & 342.74 & 4512.7 & 0.000520 \\
9 & 50.32 & 369.86 & 4640.7 & 0.000467 \\
10 & 54.01 & 396.98 & 4802.1 & 0.000401 \\
& $I=2.8559$ in. ${ }^{4} /$ in. & $R_{2}=504.41 \mathrm{~b} /$ in. \\
\hline
\end{tabular}


We may observe in Table 2 that the end slope $\theta_{A}$ increases from Station 1 to a maximum value at Station 5 and then continously decreases to Station 10. The mid-span deflections given in Table 3 also follow this pattern. The elastic curves are symmetrical about a horizontal plane passing through $a / 2$ and a vertical plane passing through $b / 2$. The deflection patterns at Stations 1, 5, and 10 are illustrated in Figs. 9, 10, and 11, respectively, and the data for these graphs were taken from Table 3 .

ORNL Dwg. 67-9071

ORNL DWg 67-9072

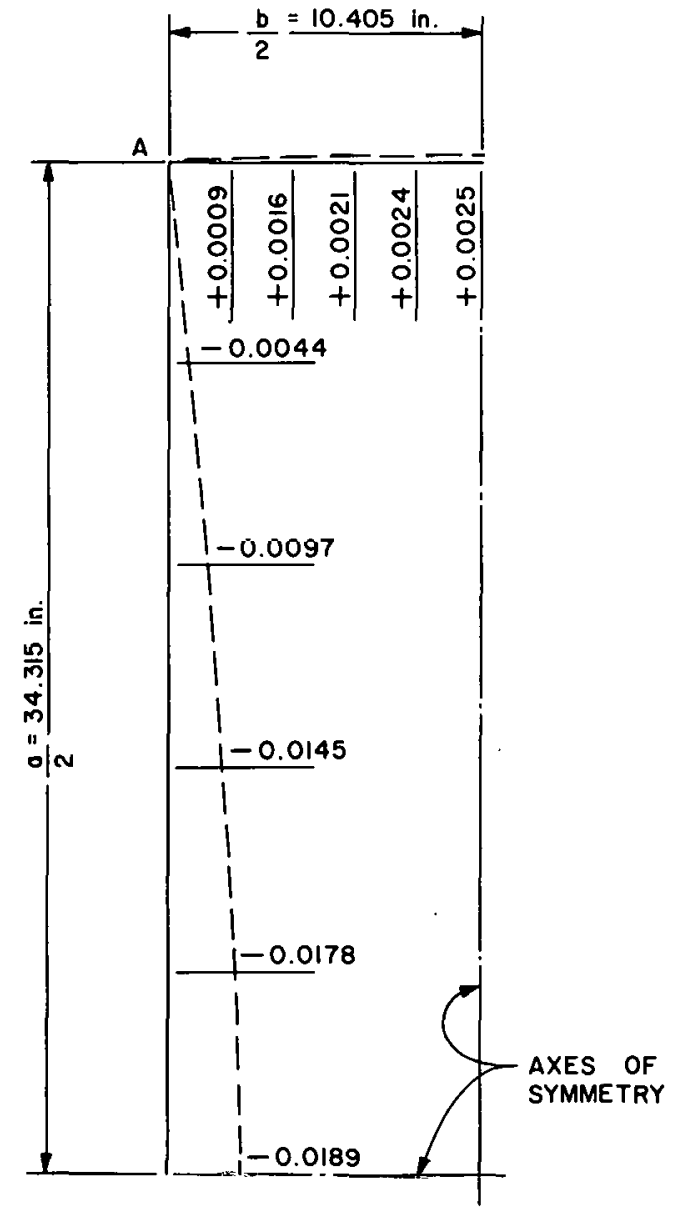

Fig. 9. Deflection Pattern at Station 1 of Double-Gap Cavity of Numerical Example 1 .

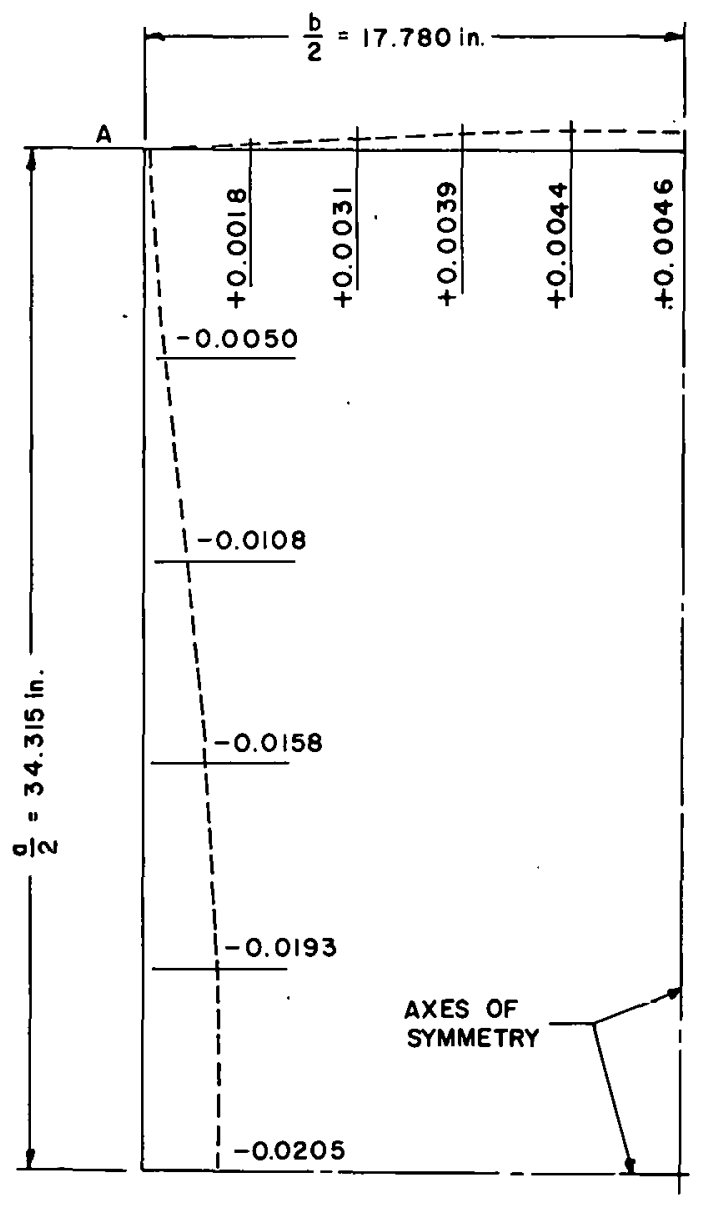

Fig. 10. Deflection Pattern at Station 5 of Double-Gap Cavity of Numerical Example 1. 
Table 3. Comfuter Frogram CCAXCAV-5 Output for Defleztions at 10 Stations of Double-Gap Cavity in Numezical Example 1

\begin{tabular}{|c|c|c|c|c|c|c|c|c|c|c|c|c|c|}
\hline & & & & & & NJEMALIZ & ED DISTA & NCE ALOI & SPAN & & & & \\
\hline STATIOI & & 0.0 & & 0.1 & 0.2 & 0.3 & 0.4 & 0.5 & 0.6 & 0.7 & 0.8 & 0.9 & 1.0 \\
\hline 1 & $\begin{array}{l}y_{a}= \\
y_{b}=\end{array}$ & & $\begin{array}{l}0 \\
0\end{array}$ & $\begin{array}{r}-.0044 \\
.0009\end{array}$ & $\begin{array}{r}-.0097 \\
.0016\end{array}$ & $\begin{array}{r}-.0145 \\
.0021\end{array}$ & $\begin{array}{r}-.0178 \\
.0024\end{array}$ & $\begin{array}{r}-.0189 \\
.0025\end{array}$ & $\begin{array}{r}-.0178 \\
.0024\end{array}$ & $\begin{array}{r}-.0145 \\
.0021\end{array}$ & $\begin{array}{r}-.0097 \\
.0016\end{array}$ & $\begin{array}{r}-.0044 \\
.0009\end{array}$ & $\begin{array}{r}-.0000 \\
0\end{array}$ \\
\hline 2 & $\begin{array}{l}y_{a}= \\
y_{b}=\end{array}$ & & $\begin{array}{l}0 \\
0\end{array}$ & $\begin{array}{r}-.0047 \\
.0012\end{array}$ & $\begin{array}{r}.0102 \\
.0021\end{array}$ & $\begin{array}{r}-.0151 \\
.0027\end{array}$ & $\begin{array}{r}-.0185 \\
.0031\end{array}$ & $\begin{array}{r}-.0197 \\
.0032\end{array}$ & $\begin{array}{r}-.0185 \\
.0031\end{array}$ & $\begin{array}{r}-.0151 \\
.0027\end{array}$ & $\begin{array}{r}-.0102 \\
.0021\end{array}$ & $\begin{array}{r}-.0047 \\
.0012\end{array}$ & $\begin{array}{l}-0 \\
-0\end{array}$ \\
\hline 3 & $\begin{array}{l}y_{a}= \\
y_{b}=\end{array}$ & & $\begin{array}{l}0 \\
0\end{array}$ & $\begin{array}{r}-.0049 \\
.0014\end{array}$ & $\begin{array}{r}-.0106 \\
.0025\end{array}$ & $\begin{array}{r}-.0156 \\
.0032\end{array}$ & $\begin{array}{r}-.0190 \\
.0036\end{array}$ & $\begin{array}{r}-.0202 \\
.0038\end{array}$ & $\begin{array}{r}-.0190 \\
.0036\end{array}$ & $\begin{array}{r}-.0156 \\
.0032\end{array}$ & $\begin{array}{r}-.0106 \\
.0025\end{array}$ & $\begin{array}{r}-.0049 \\
.0014\end{array}$ & $\begin{array}{r}-.000 J \\
-3\end{array}$ \\
\hline 4 & $\begin{array}{l}y_{a}= \\
y_{b}=\end{array}$ & & $\begin{array}{l}0 \\
0\end{array}$ & $\begin{array}{r}-.0050 \\
.0016\end{array}$ & $\begin{array}{r}-.0107 \\
.0028\end{array}$ & $\begin{array}{r}-.0158 \\
.0036\end{array}$ & $\begin{array}{r}-.0192 \\
.0041\end{array}$ & $\begin{array}{r}-.0205 \\
.0043\end{array}$ & $\begin{array}{r}-.0192 \\
.0041\end{array}$ & $\begin{array}{r}-.0158 \\
.0036\end{array}$ & $\begin{array}{r}-.0107 \\
.0028\end{array}$ & $\begin{array}{r}-.0050 \\
.0016\end{array}$ & -3 \\
\hline 5 & $\begin{array}{l}y_{a}= \\
y_{b}=\end{array}$ & & $\begin{array}{l}0 \\
0\end{array}$ & $\begin{array}{r}-.0050 \\
.0018\end{array}$ & $\begin{array}{r}-.0108 \\
.0031\end{array}$ & $\begin{array}{r}-.0158 \\
.0039\end{array}$ & $\begin{array}{r}-.0193 \\
.0044\end{array}$ & $\begin{array}{r}-.0205 \\
.0046\end{array}$ & $\begin{array}{r}-.0193 \\
.0044\end{array}$ & $\begin{array}{r}-.0158 \\
.0039\end{array}$ & $\begin{array}{r}-.0108 \\
.0031\end{array}$ & $\begin{array}{r}-.0050 \\
.0018\end{array}$ & $\begin{array}{r}-1] \\
1]\end{array}$ \\
\hline 6 & $\begin{array}{l}y_{a}= \\
y_{b}=\end{array}$ & & $\begin{array}{l}0 \\
0\end{array}$ & $\begin{array}{r}-.0049 \\
.0019\end{array}$ & $\begin{array}{r}-.0106 \\
.0032\end{array}$ & $\begin{array}{r}-.0157 \\
.0040\end{array}$ & $\begin{array}{r}-.0191 \\
.0045\end{array}$ & $\begin{array}{r}-.0203 \\
.0046\end{array}$ & $\begin{array}{r}-.0191 \\
.0045\end{array}$ & $\begin{array}{r}-.0157 \\
.0040\end{array}$ & $\begin{array}{r}-.0106 \\
.0032\end{array}$ & $\begin{array}{r}-.0049 \\
.0019\end{array}$ & $\begin{array}{r}-1) \\
0\end{array}$ \\
\hline 7 & $\begin{array}{l}y_{a}= \\
y_{b}=\end{array}$ & & $\begin{array}{l}0 \\
0 .\end{array}$ & $\begin{array}{r}. .0048 \\
.0020\end{array}$ & $\begin{array}{r}-.0103 \\
.0032\end{array}$ & $\begin{array}{r}-. J 153 \\
. .0039\end{array}$ & $\begin{array}{r}-.0187 \\
.0043\end{array}$ & $\begin{array}{r}-.0199 \\
.0044\end{array}$ & $\begin{array}{r}-.0187 \\
.0043\end{array}$ & $\begin{array}{r}-.0153 \\
.0039\end{array}$ & $\begin{array}{r}-.0103 \\
\cdot .0032\end{array}$ & $\begin{array}{r}-.0048 \\
.0020\end{array}$ & $\begin{array}{r}-0 \\
0\end{array}$ \\
\hline 8 & $\begin{array}{l}y_{a}= \\
y_{b}=\end{array}$ & & $\begin{array}{l}0 \\
0\end{array}$ & $\begin{array}{r}-.0045 \\
.0019\end{array}$ & $\begin{array}{r}-.0099 \\
.0030\end{array}$ & $\begin{array}{r}-.10147 \\
.10036\end{array}$ & $\begin{array}{r}-.0180 \\
.0038\end{array}$ & $\begin{array}{r}-.0192 \\
.0039\end{array}$ & $\begin{array}{r}-.0180 \\
. .0038\end{array}$ & $\begin{array}{r}-.0147 \\
.0036\end{array}$ & $\begin{array}{r}-.0099 \\
.0030\end{array}$ & $\begin{array}{r}-.0045 \\
.0019\end{array}$ & $\begin{array}{r}-.0000 \\
0\end{array}$ \\
\hline 9 & $\begin{array}{l}y_{a}= \\
y_{b}=\end{array}$ & & $\begin{array}{l}0 \\
0\end{array}$ & $\begin{array}{r}-.0042 \\
.0017\end{array}$ & $\begin{array}{r}-.0093 \\
.0025\end{array}$ & $\begin{array}{r}-.10140 \\
.0028\end{array}$ & $\begin{array}{r}-.0171 \\
.0029\end{array}$ & $\begin{array}{r}-.0183 \\
.0029\end{array}$ & $\begin{array}{r}-.0171 \\
.0029\end{array}$ & $\begin{array}{r}-.0140 \\
.0028\end{array}$ & $\begin{array}{r}-.0093 \\
.0025\end{array}$ & $\begin{array}{r}-.0042 \\
.0017\end{array}$ & $\begin{array}{r}-.0000 \\
-0\end{array}$ \\
\hline 10 & $\begin{array}{l}y_{a}= \\
y_{b}=\end{array}$ & & $\begin{array}{l}0 \\
0\end{array}$ & $\begin{array}{r}-.0038 \\
.0014\end{array}$ & $\begin{array}{r}-.0086 \\
.0019\end{array}$ & $\begin{array}{r}-.0130 \\
.0018\end{array}$ & $\begin{array}{r}-.0160 \\
.0016\end{array}$ & $\begin{array}{r}-.0171 \\
.0015\end{array}$ & $\begin{array}{r}-.0160 \\
.0016\end{array}$ & $\begin{array}{r}-.0130 \\
.0018\end{array}$ & $\begin{array}{r}-.0086 \\
.0019\end{array}$ & $\begin{array}{r}-.0038 \\
.0014\end{array}$ & $\begin{array}{l}-c \\
-c\end{array}$ \\
\hline
\end{tabular}


ORNL Dwg. 67-9073

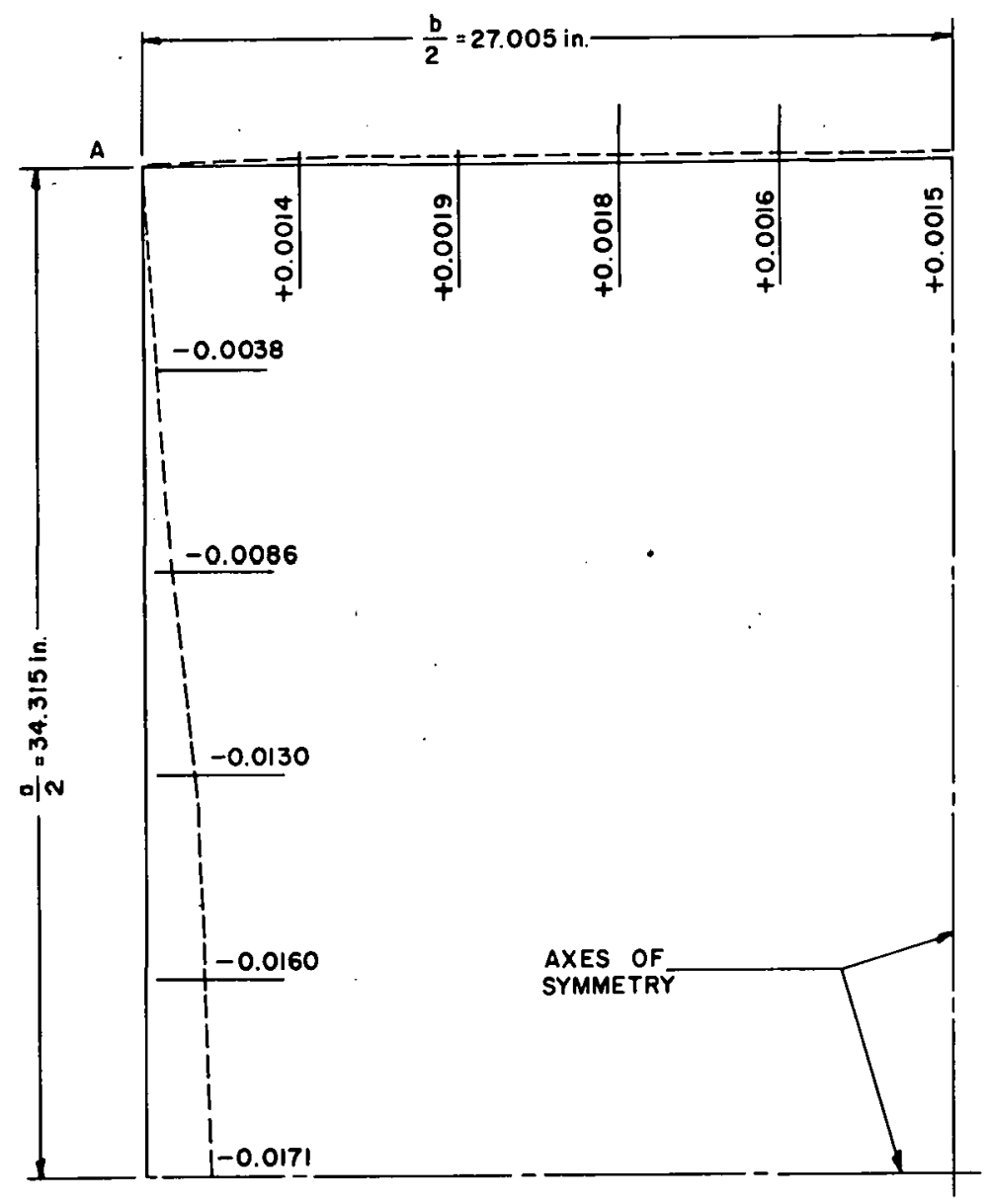

Fig. 11. Deflection Pattern at Station 10 of Double-Gap Cavity of Numerical Example 1.

Particularly notice the elastic curve of span b at Station 10 shown in Fig. 11. The deflection is zero at zero distance, reaches a maximum at about a normalized distance of 0.2 , passes through a minimum at midspan, reaches a second maximum at normalized distance 0.8 , and falls off to zero at normalized distance 1.0 . Notice also that in this particular example, the deflections of span a are always inward (negative) and the deflections of span b are always outward (positive). We would suggest that the deflections of span $b$ would become negative in the region near mid-span if the cavity were lengthened a sufficient amount and the same side taper were kept.

The data for the cavity used in this example are that of the prototype for a 50-Mev separated orbit cyclotron. The dimensions given are 
those of the prototype as it was fabricated. The cavity is stiffened by 'l'-beams (S'I' 6B X y.5) spaced 21.35 in. center to center. Based on an equivalent plate thickness, $t_{e}$, of 0.461 in., the actual value of $I$ obtained is 2.727 in. ${ }^{4} /$ in. This compares favorably with the computed required value of $2.856 \mathrm{in.}{ }^{4} / \mathrm{in}$. given in Table 2 .

\section{Example 2}

For the second example, consider the double=gap cavity without side stays illustrated in Fig. 3. The dimensions of the cavity for this example are shown in Fig. 12.

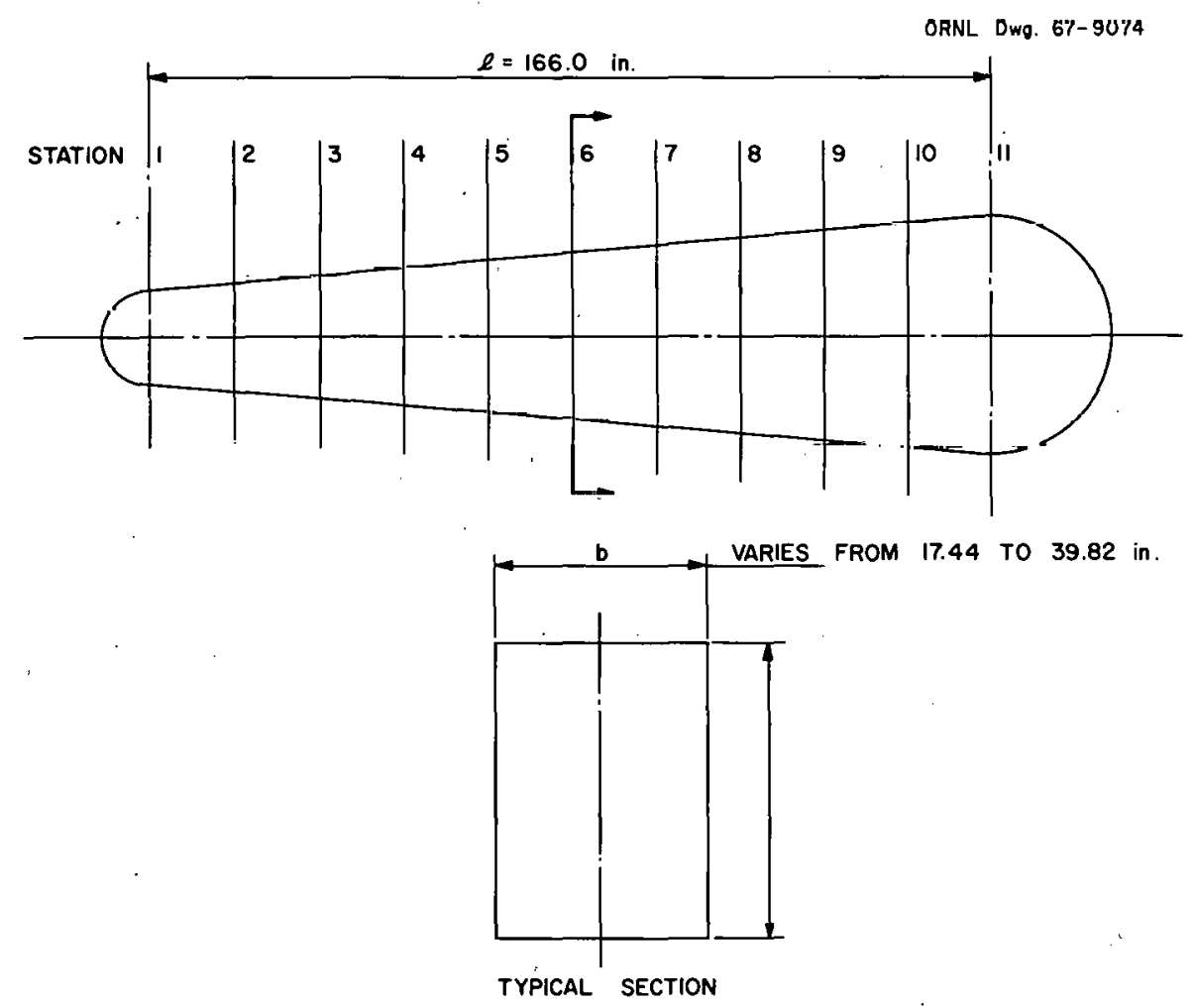

Fig. 12. Dimensions of Double-Gap Cavity Without Side Stays for Numerical Example 2. 
In this example, the flexural rigidity, EI, and consequently the second moment of area, I, of the walls are allowed to vary along the length of the cavity while $I_{a}=I_{b}=I$ at any section taken normal to $l$. The values of $I$ are to be determined at each of the 11 equally spaced stations shown in Fig. 12, and they are to be based upon a series of specified maximum deflections of side $a, y_{a}$ max, at each of the 11 stations. Beginning at Station 1, these values increase nearly linearly along the length of the cavity to the maximum value at Station 11.

Following the specification of the 11 values of $\mathrm{y}_{\mathrm{a} \max }$ and the computation of $I$ at each station, values for $R_{1}, M_{1}, \theta_{A}$, and the deflection curves were obtained in the same manner as they were for Example 1. The computations were performed by using a computer program called COAXCAV-3, which is essentially the same as COAXCAV-5 except for the deflection condition input, the calculation of 11 values of I Instead of one, and the resulting changes in the output format. The computer program COAXCAV-3 output for widths, second moments of area, reactions, moments, and end slopes for the maximum deflections specified are given in Table 4, and the output for the deflection data at the 11 stations are given in Table 5 . 
Table 4. Computer Program COAXCAV-3 Cutput for Wädths, Second Monents of Area, Reactions, Moments, and Enc Slopes for the Maximcm Deflections Specified at 11 Stations of Double-sap Cavity in Numerical Example 2

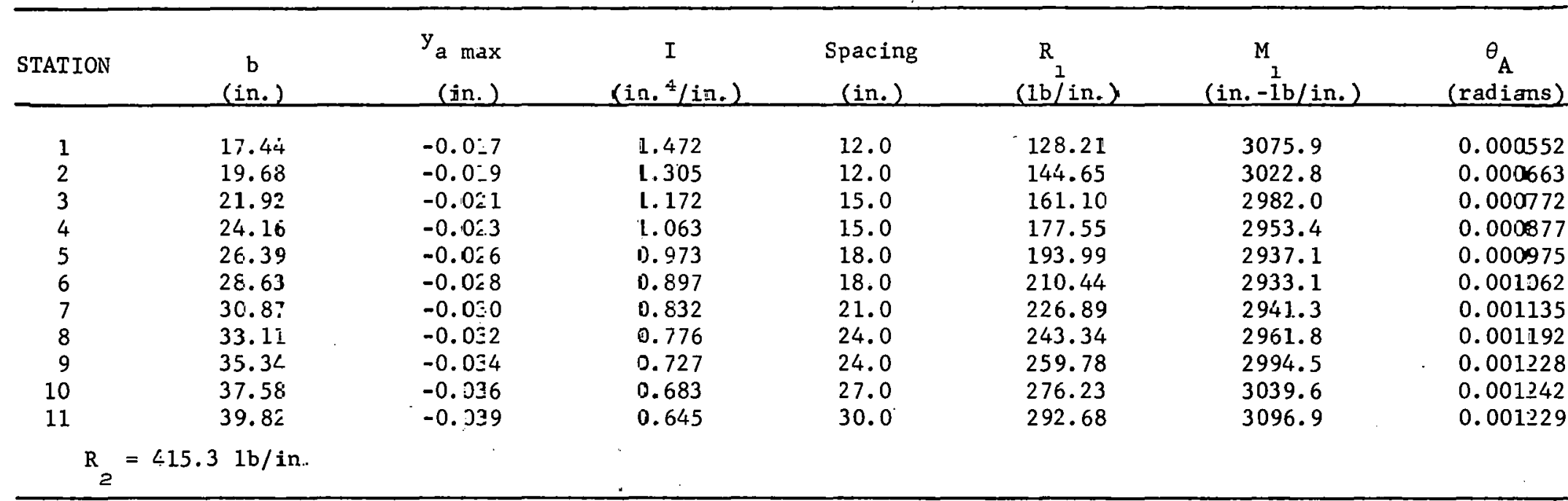


Table 5. Computer Program COAXCAV-3 Output for Deflections at 11 Stations of Double-Gap Cavity in Numerical Example 2

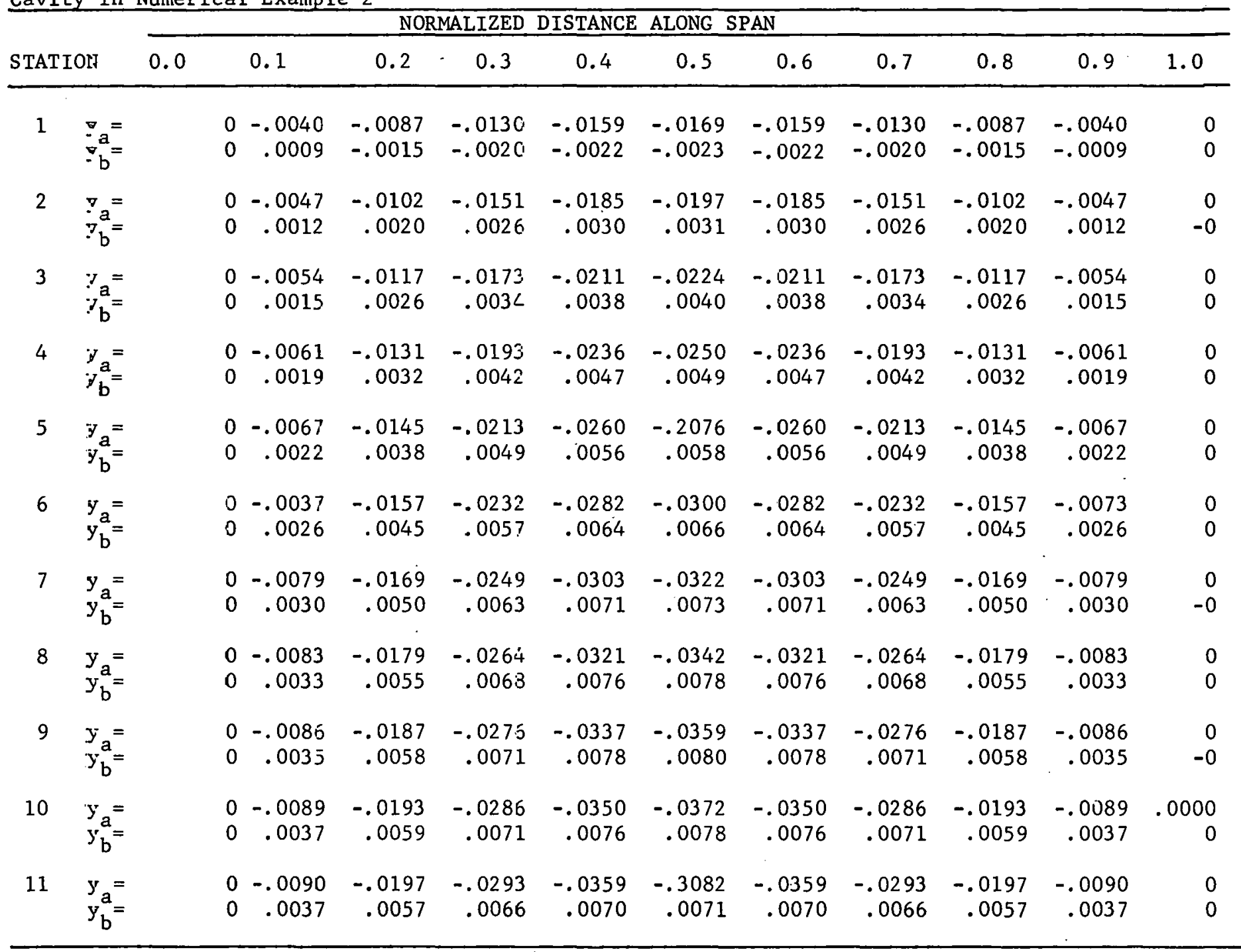


Again, we find that the elastic curves are symmetrical as they wcre in Example 1. The deflection patterns at Stations 6 and 11 are shown graphically in Figs. 13 and 14, respectively, and the data for these graphs were taken from Table 5. Because of the varying flexural rigidity, the deflection pattern is somewhat different from that in Example 1. The end slope $\theta_{A}$ increases continuously from Station 1 through Station 11. The mid-span deflections of span $b$ (the top and bottom of the cavity) increase continuously from Station 1 through Station 9 and then decrease slightly at stations 10 and 11 . There are no points of inflection in the elastic curves, as previously noted.

ORNL DWg. 67-9075

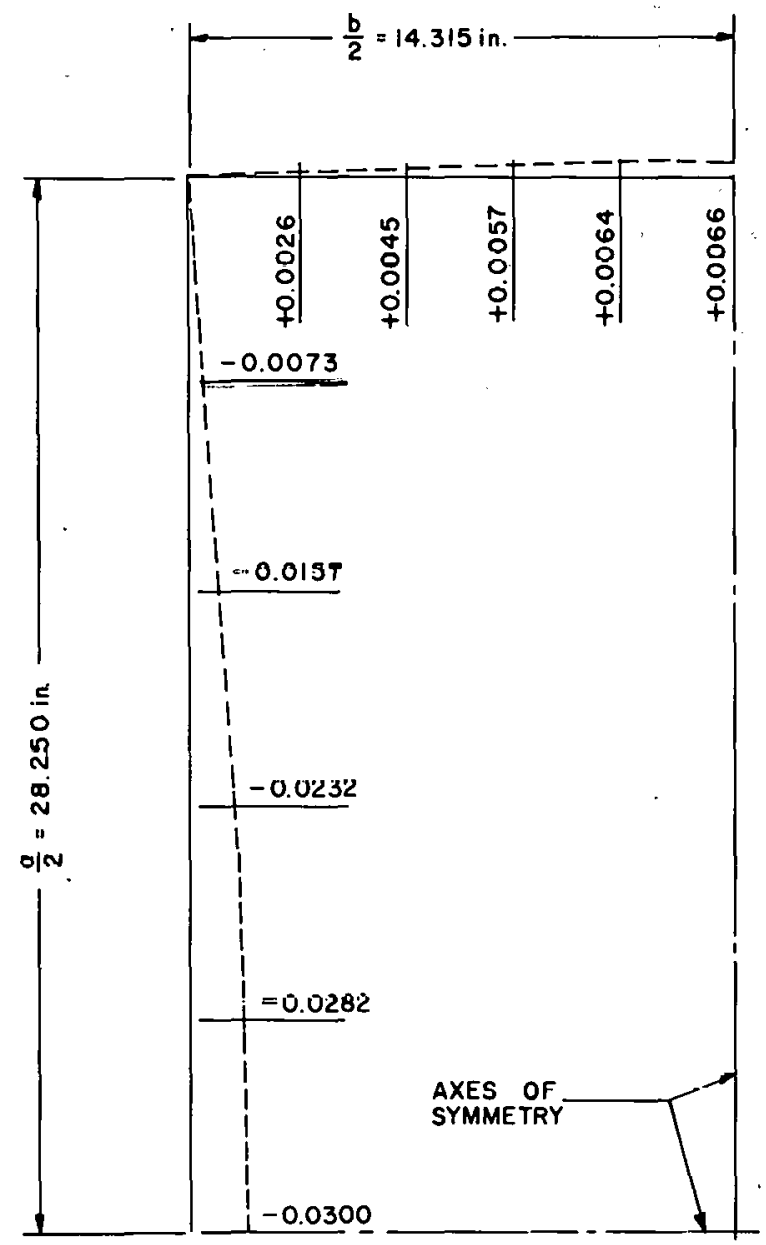

Fig. 13. Deflection Pattern at Station 6 of Double-Gap Cavity of Numerical Example 2. 


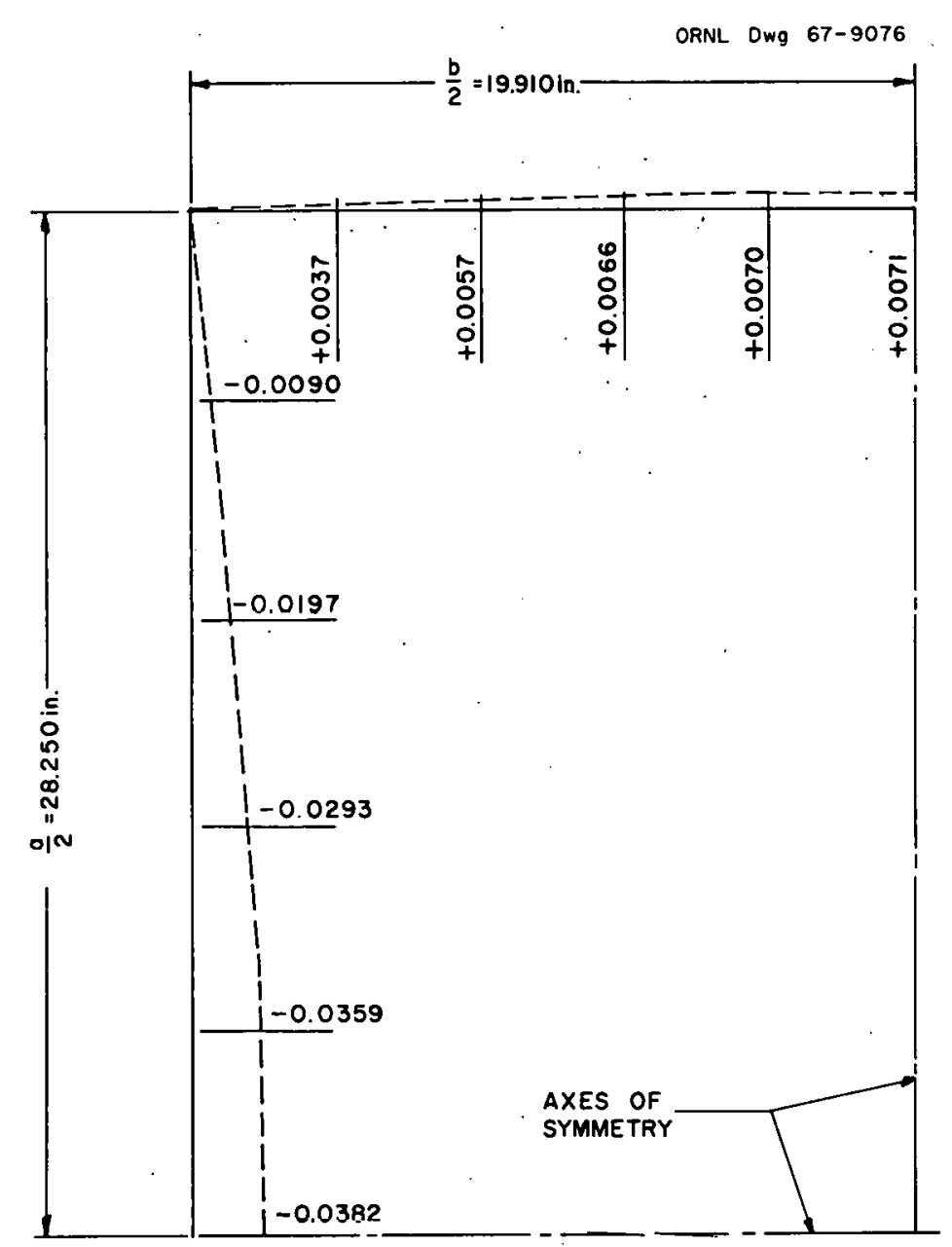

Fig. 14. Deflection Patterns at Station 11 of Double-Gap Cavity of Numerical Example 2 .

The variable second moment of area, I, may be satisfactorily approximated for the values computed by using $T$-beams (ST $4 \mathrm{~B} \times 6.5$ on a plate with an equivalent thickness of 0.461 in.) on a variable spacing. The approximate spacing required is given in column 5 of Table 4.

\section{Example 3}

Again consider the cavity in Example 2 dimensioned in Fig. 12. For this example, the series of maximum deflections on span a are imposed as they were in Example 2, and in addition, the condition that $y_{b} \max =0.080$ 
in. at each of the 11 stations is imposed. 'lherefore, $I_{a}$ will not necessarily be equal to $I_{h}$ at any section taken normal $u \in$, and both $\mathrm{I}_{a}$ and $I_{b}$ will vary along $l$. The values for $I_{a}$ and $I_{b}$ to be determined at each of the 11 stations are to be based on the imposed deflection requirements.

The values of $I_{a}$ and $I_{b}$ cannot be determined directly from Eqs. 1 and 2 because the expression for $M_{1}$ given in Eq. 3 and the expression for the end slope $\theta_{A}$ given in Eq. 4 are functions of both $I_{a}$ and $I_{b}$. They are found by using the iterative procedure described in the following material.

At each of the 11 stations, an initial eslimate was made for the values of $I_{a}$ and $I_{b}$ from expressions for the millespan deflection of $a$ uniformly loaded beam with fully constrained ends. For the first estimate,

and

$$
I_{a}=\frac{w a^{4}}{384.0 E \triangle_{a}}
$$

$$
I_{b}=\frac{w b^{4}}{384.0 E \triangle_{b}} \text {, }
$$

where $\Delta_{a}$ and $\hat{\Delta}_{b}$ represent the imposed deflection conditions stated above. In the second step of this procedure, values for $M_{I}$ and $\theta_{A}$ were calculated from Eqs. 3 and 4 by using the values estimated for $I_{d}$ and $I_{b}$. The thisd step of the prucedure consisted of computing $y_{a} \max$ from Eq. 1 by setting $x=a / 2$ and using the values obtained.in the first two steps of this procedure and of computing $y_{b} \max$ from Eq. 2 by setting $x-b / 2$. These calculaled values will in all probabllicy differ from the stated imposed deflection conditions. Therefore, $I_{a}$ and $I_{b}$ must be adjusted.

and

$$
I_{a}(\text { new })=I_{a}(\text { old }) \frac{y_{a \max }}{\Delta_{a}}
$$

$$
I_{b} \text { (new) }=I_{a}(01 d) \frac{y_{b} \text { max }}{\Delta_{b}} .
$$

With new values for $I_{a}$ and $I_{b}$, the fifth step of this procedure consisted of returning to the second step and calculating new values for $M_{1}$ and $\theta_{A}$. The procedure was continued until 


$$
\frac{y_{a \max }}{\Delta_{a}} \leq|\mathrm{k}|
$$

and

$$
\frac{y_{b} \max }{\Delta_{b}} \leq|k|
$$

where $k$ = some specified convergence condition.

The values for $b, I_{a}, I_{b}, R_{I}, M_{I}$, and $\theta_{A}$ were computed at each of the 11 stations by using a computer program called COAXCAV-2. Values for $\mathrm{R}_{2}$ and the deflection curves were also computed by using the program. The important difference between program COAXCAV-2 and the COAXCAV-3 program used for Example 2 is that COAXCAV-2 performs the iterative procedure just described. It also has a different deflection condition input and a different output format. The values computed for the widths, second moments of area, reactions, moments, and end slopes for the specified maximum deflections at the 11 stations of the double-gap cavity in Example 3 are given in Table 6, and the computed deflection data are given in Table 7 . 
Table 6. Computer Program CJAXCAV-2 Output for Widths, Second Moments of Area, Reactions, Moments, and End SlcFes for the Maximum Deflections Specified at 11 S-ations of Double-Gap Cavity in Numerical Example 3.

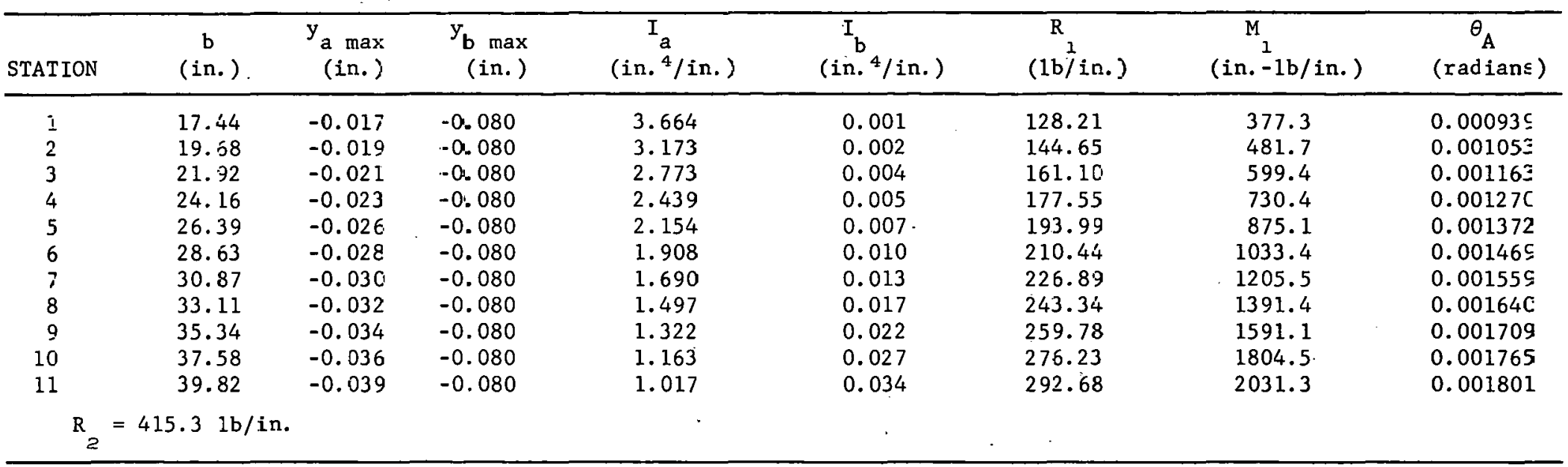


Table 7. Computer Program COAXCAV-2 Output for Deflections at 11 Stations of Double-Gap Cavity in Numerical Example 3

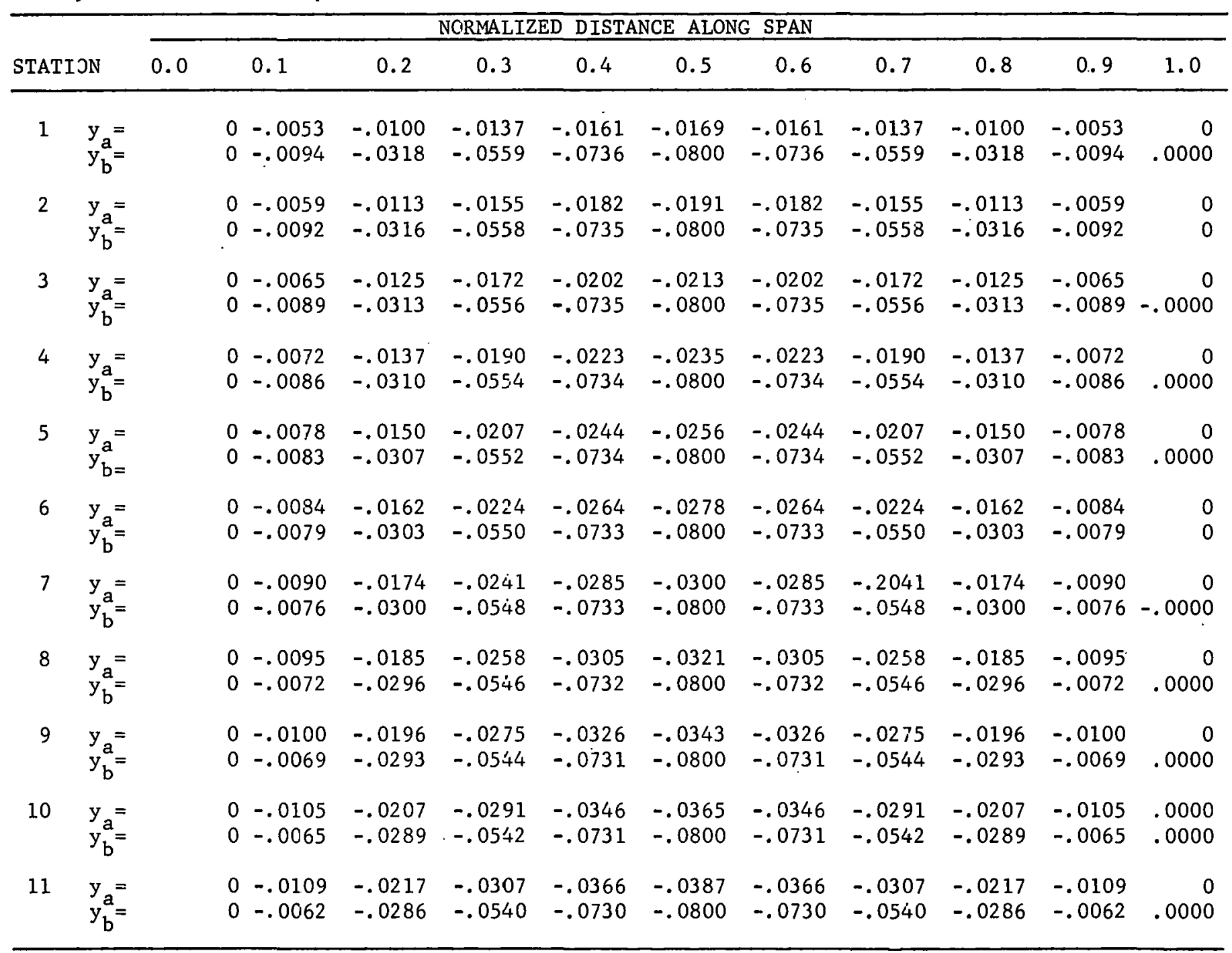


As in Example 2, we again find that the elastic curves are symmetrical. The deflection patterns at Stations 1 and 11 are $i 11$ us trated graphically in Figs. 15 and 16, respectively, and the data for these graphs were taken from Table 7.

Judging from the range of values of $I_{a}$ and $I_{b}$ given in Table 6 , it might be concluded that this approach has no practical application in the design of radio frequency cavities, and it might also be suspected that the range of validity of the assumptions made has been exceeded. That is, if a cavity structure were built with the variable flexural rigidity indicated, it is not certain that the deflection behavior would be similar to that indicated by the rnmputations.

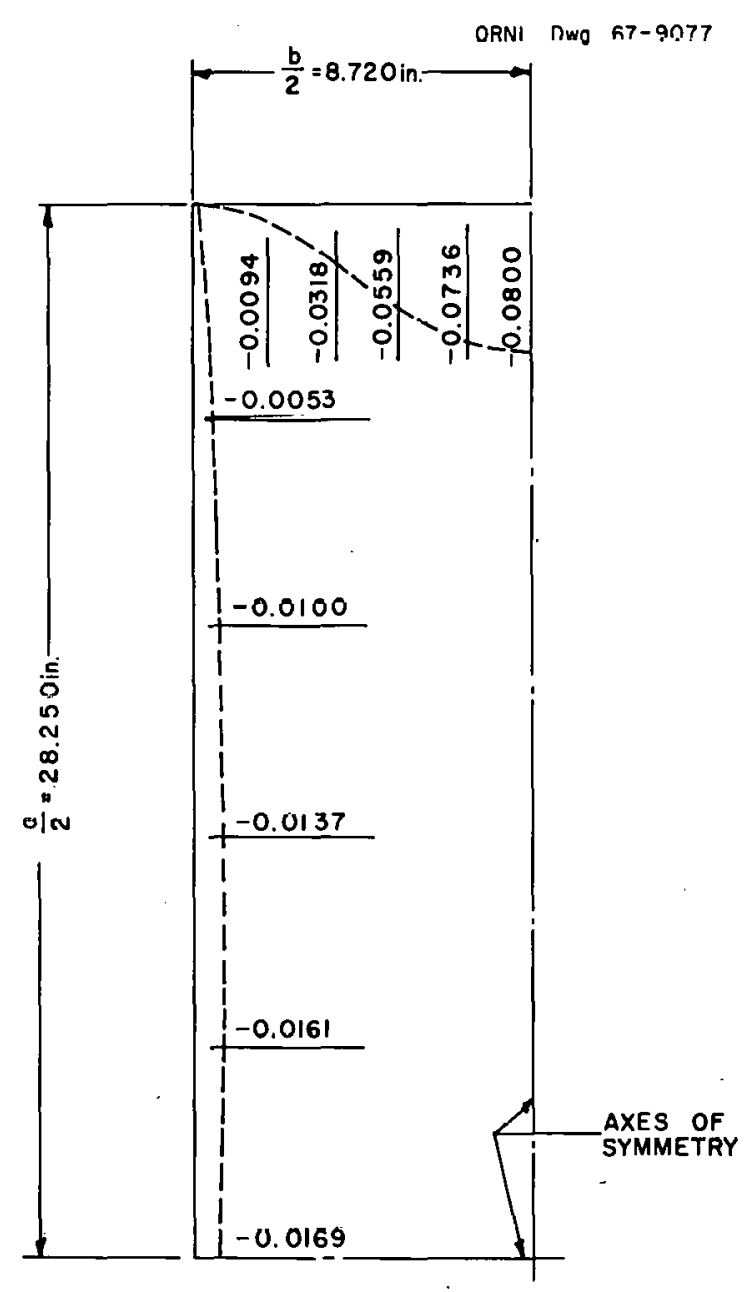

Fig. 15. Deflection Pattern at Station 1 of the Double-Gap Cavity of Numerical Example 3. 


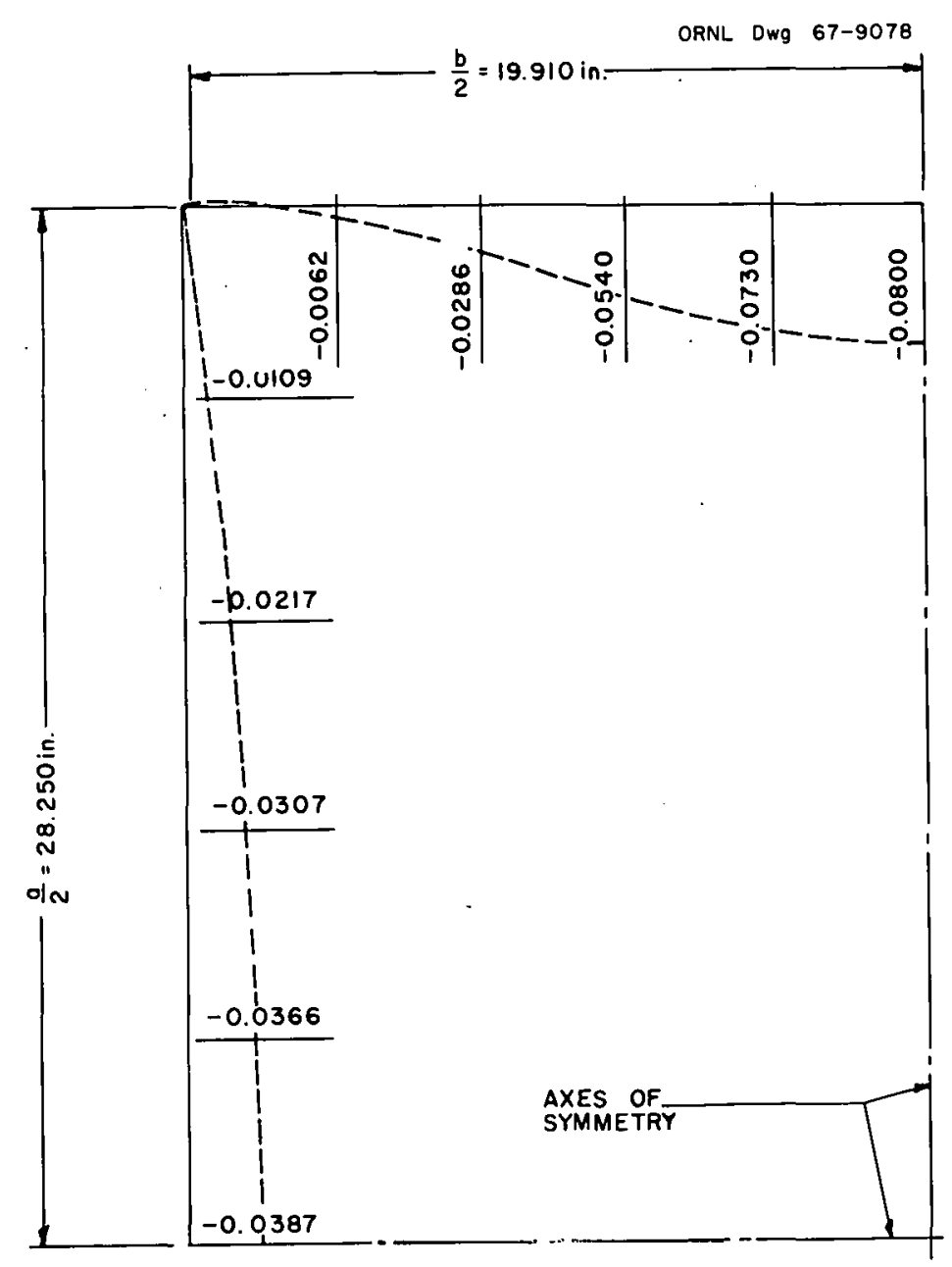

Fig. 16. Deflection Pattern at Station 11 of the Double-Gap Cavity of Numerical Example 3.

\section{Example 4}

The single-gap cavity with flat tapered sides, flat parallel top and bottom, flat ends, and side stays illustrated in Fig. 2 is considered in this example. If the curvature of the top and bottom of the cavity is slight, the sides may be considered as being rectangular. For this example, it was assumed that all sections normal to the lengthwise direction are the same, and the dimensional designations for these sections are illustrated in Fig. D. 1 of Appendix D. For this example, $a=44.5$ in., $b=44.5$ in., and $c=85.0$ in. The derivations for this example are given in Appendix D, and the reactions and moments are shown in Fig. D. 2 . 
The following deflection condition was imposed for this example.

$$
y_{a(x=a / 2)}=y_{b(x=b / 2)}-y_{c(x=c / 2)}=\Delta=0.030 \text { in. }
$$

The second moments of area $I_{a}, I_{b}$, and $I_{c}$ will be made to take on values that satisfy the imposed deflection condition. Values for $I_{a}$, $I_{b}$, and $I_{c}$ cannot be determined directly from expressions already derived, but they were determined by using the iterative procedure described in the following material.

The first step in the iterative procedure was to make an initial estimate of the values of $I_{a}, I_{b}$, and $I_{c}$ by using expressions for the mid-span deflection of a uniformly loaded beam with fully constrained ends. For this first estimate,

$$
\begin{aligned}
& I_{a}=\frac{w a^{4}}{384 \cdot 0 \mathrm{E} \triangle}, \\
& I_{b}=\frac{w b^{1}}{384.0 E \triangle},
\end{aligned}
$$

and

$$
I_{c}=\frac{W c^{4}}{384.0 \mathrm{E} \Delta}
$$

Using these estimated values, the second step involved computing the values for $R_{3}, M_{3}, \theta_{A}, \theta_{G}$, and $M_{\perp}$ by using Eqs. 14, 15, 16, 17, and 18 derived in Appendix $C$. The third step then consisted of using these vàlues to obtain values for $y_{a}$ mid=span' $y_{b}$ mld-span, and $y_{r}$ mir-span from Eqs. 32, 33, and 34. In all probability, the values obtained will differ from the deflection conditions imposed. Therefore, the fourth step in, the procedure involves adjusting the values for $I_{a}, I_{b}$, and $I_{c}$.

$$
\begin{aligned}
& I_{a}(\text { new })=I_{a}(\text { old }) \frac{y_{a \text { mid-span }}}{\Delta}, \\
& T_{b}(\text { new })=I_{b}(\text { lld }) \frac{y_{b \text { mid-span }}}{\Delta},
\end{aligned}
$$

and

$$
I_{c} \text { (new) }=I_{c}(o l d) \frac{y_{c \text { mid-span }}}{\Delta} .
$$

With new values of $I_{a}, I_{b}$, and $I_{c}$, the second, third, fourth, and fifth steps of the procedure were repeated until 


$$
\begin{aligned}
& \frac{y_{a \text { mid-span }}}{\Delta} \leq|k|, \\
& \frac{y_{b \text { mid-span }}}{\triangle} \leq|k|,
\end{aligned}
$$

and

$$
\frac{\mathrm{y}_{\mathrm{c} \text { mid-span }}}{\Delta} \leq|\mathrm{k}|
$$

where $k$ = some specified convergence criterion.

The procedure just described would be rather tedious if performed manually; however, it is handled quickly with a computer. The iterative procedure was applied to computer values of $I_{a}, I_{b}, I_{c}, R_{3}, M_{3}, \theta_{A}, \theta_{G}$, and $M$ through the use of a computer program called CAVSAG. Values for $R_{1}, R_{2}, R_{4}, P$, and the deflection curves were also computed by using this program. The input for the program consists of sets of deflection conditions that the walls of the cavity must meet under the imposed loads and the dimensions of the cavity. The output consists of one set of data for each set of deflection conditions. Computer output data for the cavity dimensions and deflection conditions of this example are given in Table 8.

The deflection data given in Table 8 are illustrated in Fig. 17, and we again find that the elastic curves are symmetrical. In this example, the mid-span deflections of spans $a, b$, and $c$ have arbitrarily been required to equal each other. However, the mid-span deflections may differ from each other in any manner as long as the values chosen permit a real solution. If the sides of such a cavity were made from flat steel plate, the values of $I_{a}, I_{b}$, and $I_{c}$ given in Table 8 could be attained approximately by using plate thickness of

and

$$
\begin{aligned}
& t_{a}=13 / 8 \text { in. } \\
& t_{b}=11 / 4 \text { in. } \\
& t_{c}=43 / 4 \mathrm{in.}
\end{aligned}
$$

While such an arrangement might be unusual, it is quite possible. From an economical consideration, the design for such a structure would likely result in a composite.wall structure such as that illustrated in Figs. 4 and A. 1 even though the transition from one value of $I$ to one of a greater or lesser value might be difficult from a design standpoint. 
Table 8. Computer Program CAVSAG Outpu= Data for the Single-Gap Cavity of Numerical Example 4

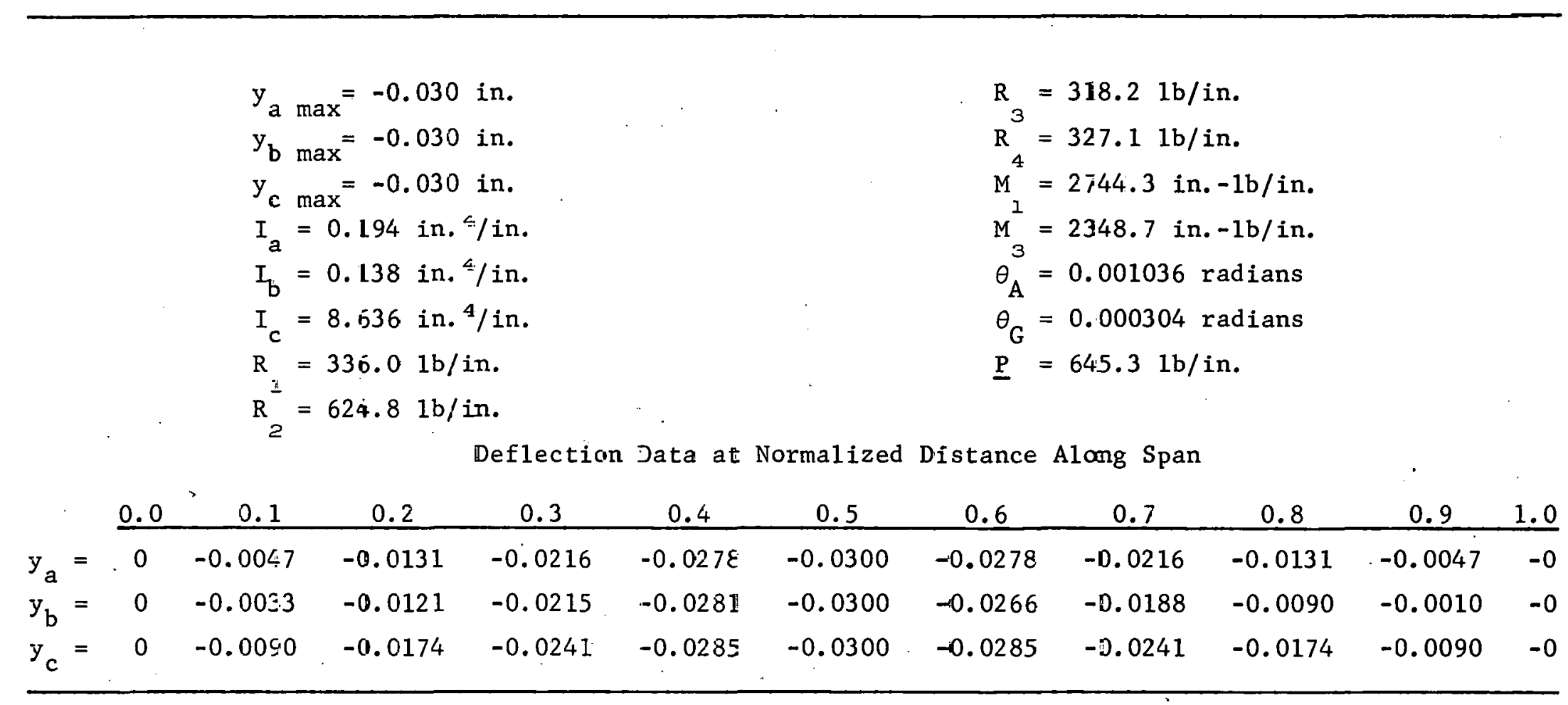




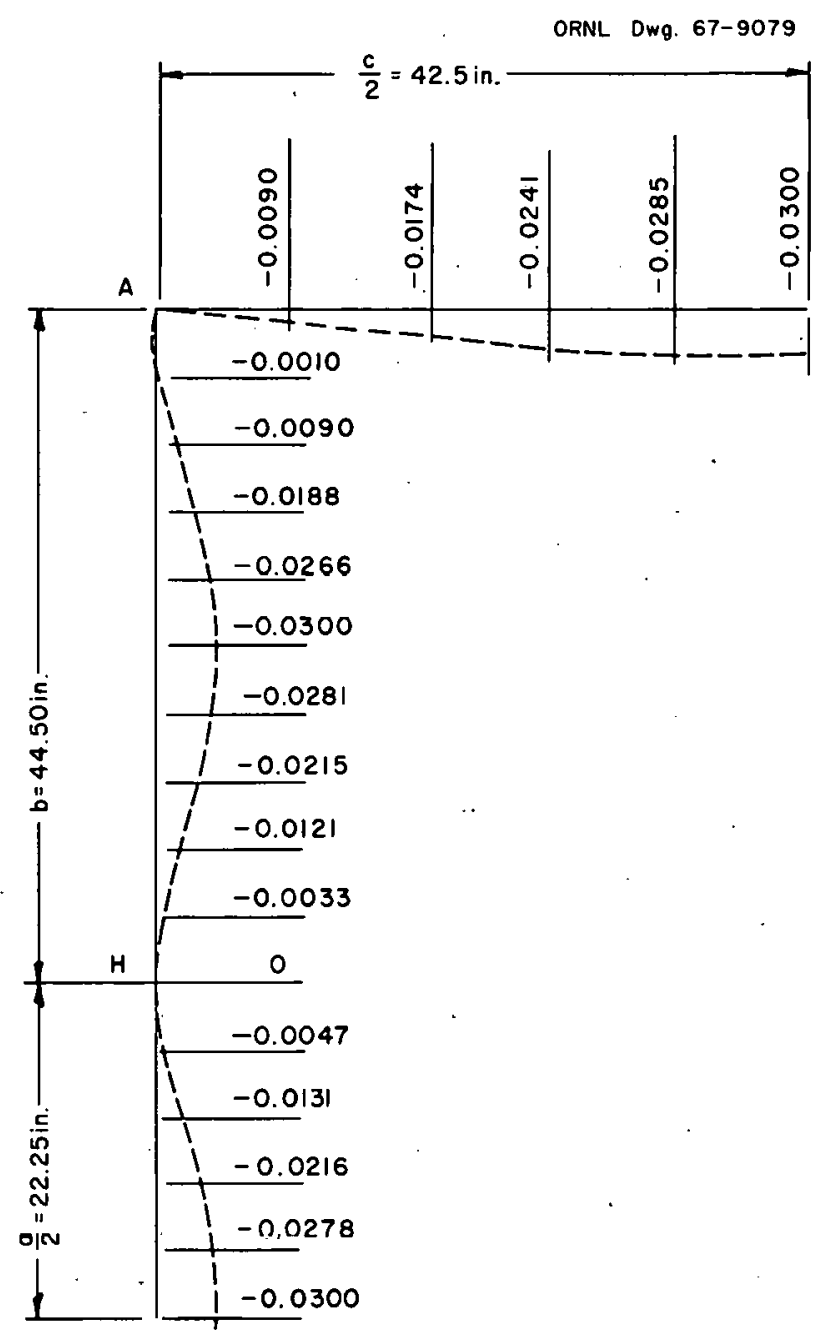

Fig. 17. Deflection Pattern for Single-Gap Cavity of Numerical Example 4 . 


\section{CONCLUSIONS}

It may be concluded from. the analysis methods developed and the numerical examples illustrating the application of the methods that flexural rigidities can be made to vary as required to obtain specified deflection patterns in radio frequency cavities. However, application of this principle to actual designs for cavities is sometimes difficult. The numerical results obtained in Examples 3 and 4 of Chapter 3 suggest the difficulty of applying this principle to any great degree in the applications considered here. In the particular case of the prototype cavity for the 50-Mev separated orbit cyclotron, consideration of the available material, the probable increase in cost, the difficultin of fabrication, and the problems in the design of the cavity resulted in the decision to use plate of the same size, stiffeners of the same size, and the same stiffener spacing all around the cavity.

Even with conscientious effort exerted in the shop to keep deviations to a minimum, experience has shown that dimensional deviations that result during fabrication may be several times greater than those caused by elastic behavior. Strong stiffeners are very helpful in controlling fabrication deviations, particularly in correcting warping of the flat plate caused by welding.

However, the principle of varying flexural rigidity and the associated derivations may be useful in certain special applications. The necessary calculating with mathematical expressions such as those derived in this report can be done with simple computer programs. Perhaps the greatest benefit derived from using computer programs in this application is the ability to use wider ranges of variability in multi-parameter calculations. Greater accuracy and closer spaced data are usually obtained by using computer programs, and while the calculatory portions of the programs are usually simple and straightforward, the output may be tedious. 
APPENDICES 
THIS P'AGE

\section{WAS INTENTIONALLY \\ LEFT BLANK}




\section{Appendix A}

\section{COMPOSITE WALL STRUCTURE CONSIDERED AS AN EQUIVALENT SOLID PLATE}

In the analyses described in this report, the flexural rigidity of a composite structure made by welding T-beam stiffeners on steel plate is considered to be equivalent to that of a solid steel plate with an equal second moment of area. The equivalent thickness of the solid plate is derived in the following material, and cross sections through the composite structure and an equivalent plate are illustrated in Fig. A.l.
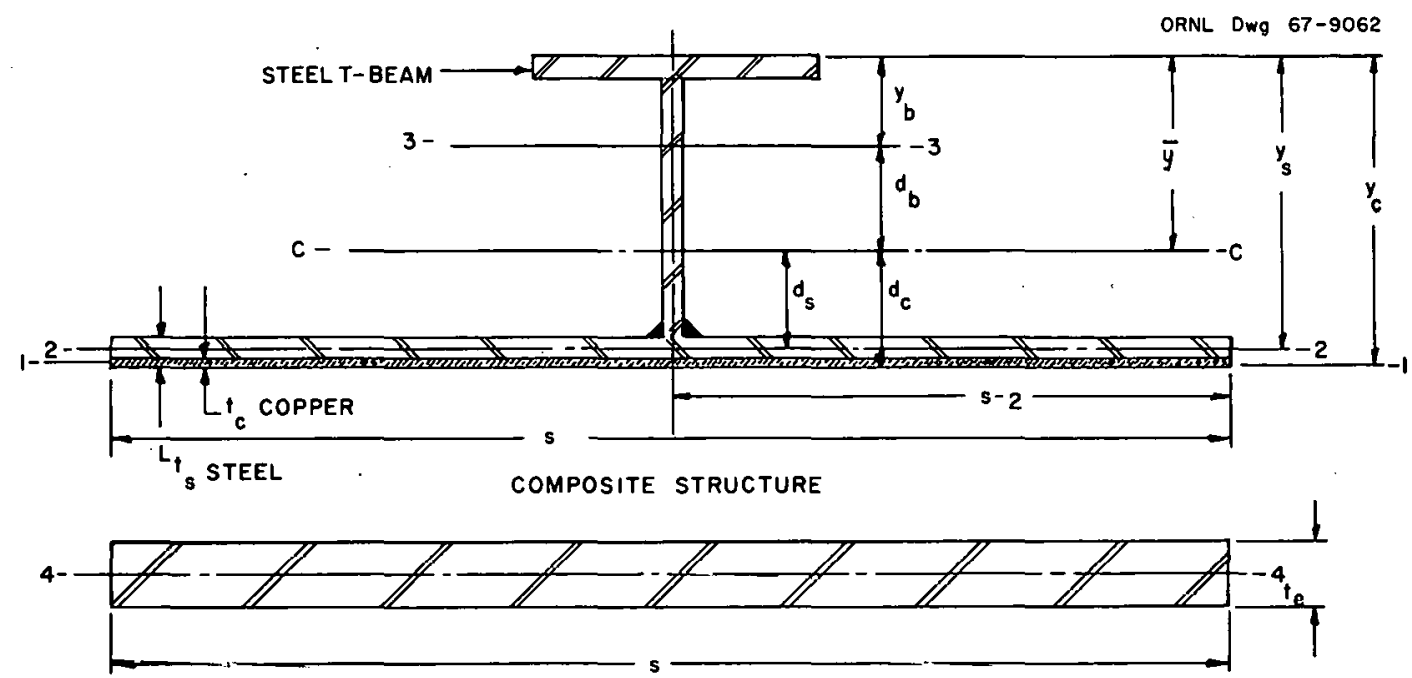

EQUIVALENT PLATE

Fig. A.1. Cross Sections Through A Composite Wall Structure and A Steel Plate of Equivalent Thickness.

The terms used to derive the equivalent thickness of a solid steel plate are defined by referring to Fig. A.I where

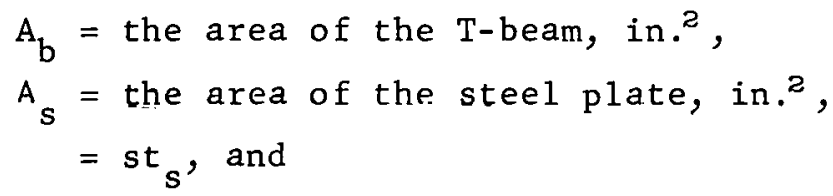




$$
\begin{aligned}
A_{c}= & \text { the equivalent area of copper cladding, in. }{ }^{2}, \\
= & \frac{F_{c}}{E_{s}} \text { st }{ }_{c}, \\
& \text { where }
\end{aligned}
$$

$$
\begin{aligned}
& E_{s}=\text { Young's modulus for steel, psi, and } \\
& E_{c}=\text { Young's modulus for copper, psi. }
\end{aligned}
$$

The location of the centroidal axis of the cumposite structure is expressed by the equation,

$$
\bar{y}_{c-c}=\frac{A_{b} y_{b}+A_{s} y_{s}+A_{c} y_{c}}{A_{b}+A_{s}+A_{c}} .
$$

The second moment of area or moment of inertia of the composite structure,

$$
I_{c-c}=T_{b_{3-3}}+\Lambda_{b} d_{b}^{2}+I_{s_{2-2}}+A_{s} d_{s}^{Z}+I_{c_{1-1}}+A_{c} d_{c}^{2} .
$$

The serond moment if ared of a solid plate equivalent in flexural rigidity to the composite structure,

$$
I_{e_{4-4}}=\frac{s t^{3}}{12}=I_{c-c} .
$$

Therefore, the equivalent thickness of a solid steel p1ate,

$$
t_{e}=\left(\frac{12 I c-c}{s}\right)^{1 / 3} \text {. }
$$


Appendix B

COPPER-CLAD STEEL PLATE CONSIDERED AS SOLID STEEL PLATE

In the calculations for panel deflections, copper-clad steel plate is regarded as solid steel plate with an equivalent thickness. The equivalent thickness of the solid steel plate is derived in the following material, and cross sections through the copper-clad plate and a solid steel plate of equivalent thickness are illustrated in Fig. B.1.
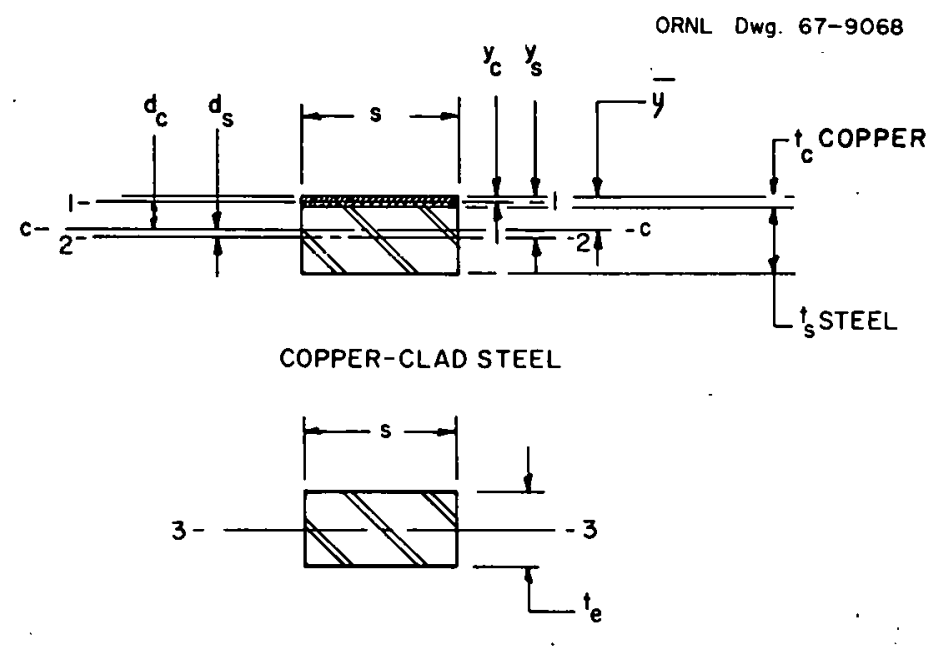

EQUIVALENT PLATE

Fig. B.1. Cruss Sections Through A Copper-Clad Steel Plate and a Solid Steel Plate With An Equivalent Thickness.

The terms used to derive the equivalent thickness of a solid steel plate are defined by referring to Fig. B.l where

$A_{s}=$ the area of the steel plate, in. ${ }^{2}$,

$=$ st $_{\mathrm{s}}$, and

$A_{c}=$ the equivalent area of the copper cladding, in. ${ }^{2}$,

$=\frac{E_{c}}{E_{s}} s t c^{\prime}$

where

$\mathrm{E}_{\mathrm{s}}=$ Young's modulus for steel, psi, and

$E_{c}=$ Young's modulus for copper, psi. 
The location of the centroidal axis of the clad plate is given by the equation

$$
\bar{y}=\frac{A_{s} y_{s}+A_{c} y_{c}}{A_{s}+A_{c}} .
$$

The second moment of area or the moment of inertia of the clad plate,

$$
I_{c-c}=I_{s_{2}-2}+A_{s} d_{s}^{2}+I_{c_{1}-1}+A_{c} d_{c}^{2} \text {. }
$$

The second moment of area of a solid plate equivalent in flexural rigidity to the clad plate,

$$
1_{e_{3-3}}=\frac{s t_{c}^{3}}{12}=I_{c-c} .
$$

Therefore, the equivalent thickness of the solid steel plate,

$$
t_{e}=\left(\frac{12 I c-c}{3}\right)^{1 / 3} \text {. }
$$




\section{Appendix C}

MATHEMATICAL DERIVATION OF ELASTIC CURVES, BENDING MOMENTS, AND END SLOPES FOR CAVITY WITHOUT SIDE STAYS

A cross-sectional slice of unit thickness taken through the cavity without side stays is shown in Fig. C.l. The height of this crosssectional slice is denoted by the letter $a$, the width by $b$, and the end slopes by $\theta_{A}, \theta_{B}, \theta_{C}$, and $\theta_{D}$ at points $A, B, C$, and $D$, respectively. The loading, $w 1 b / i n .$, is the atmospheric pressure all around the outside surface of the cavity that results when the cavity is evacuated during operation. The plane moments of inertia of the beams with spans $a$ and $b$ are $I_{a}$ and $I_{b}$, respectively. The corners at points $A, B, C$, and $D$ were assumed to be rigid but subject to rotation. Therefore, by symmetry,

$$
\begin{array}{r}
\theta_{\mathrm{A}}=\theta_{\mathrm{C}}=-\theta_{\mathrm{B}}=-\theta_{\mathrm{D}} \cdot \\
\text { ORNL Dwg. } 67-9063
\end{array}
$$

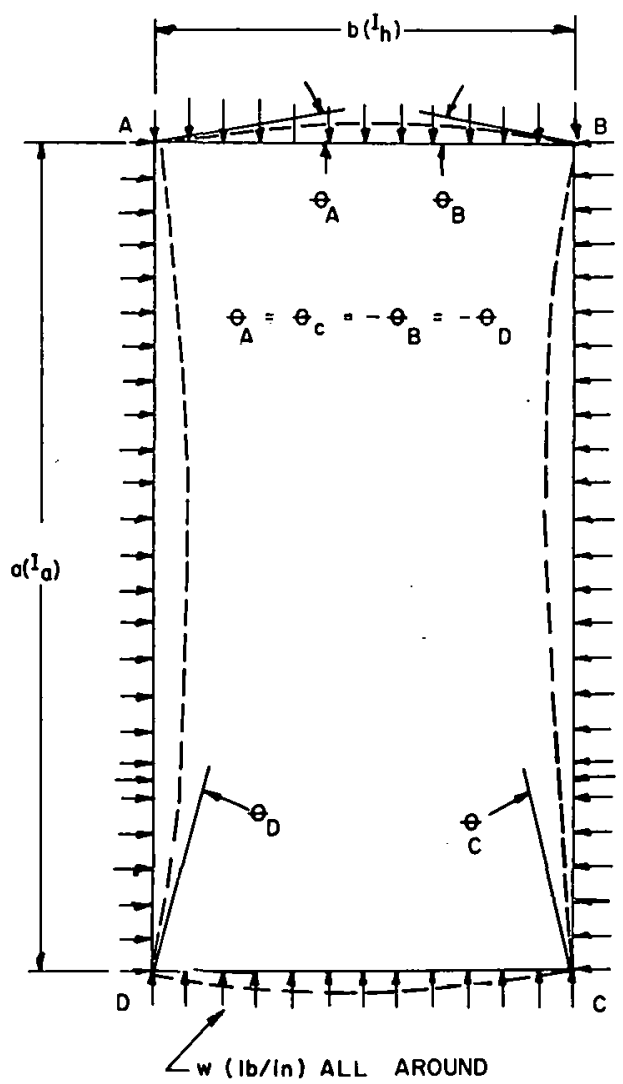

Fig, C.1. Cross-Sectional Slice of Unit Thickness Through Cavity Without Side Stays. 
To obtain expressions for the bending moments and reactions, free body diagrams of spans $a$ and $L$ were drawn, as shown in Fig. C.2, and a sign convention was adopted. Positive deflection is upward, as shown for span b in Fig. C.2. If the tangent to the elastic curve rotates counterclockwise, the angle of rotation is positive, and those moments acting in a clockwise direction on joints are positive. If deflections are small, bending moments caused by axial end reactions are small when compared with bending moments caused by transverse loads and reactions. Since the amount of deflection in the cavity must be limited to small values, we may neglect axial end reactions and simplify the mathematics greatly.

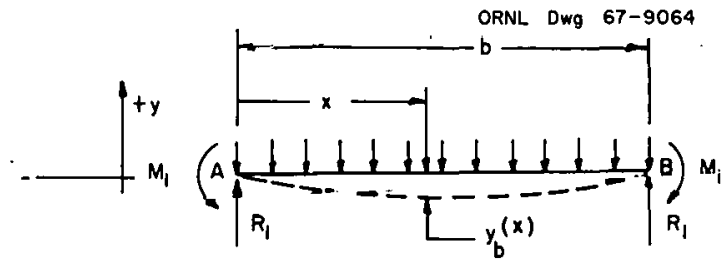

$\leftrightarrow-$

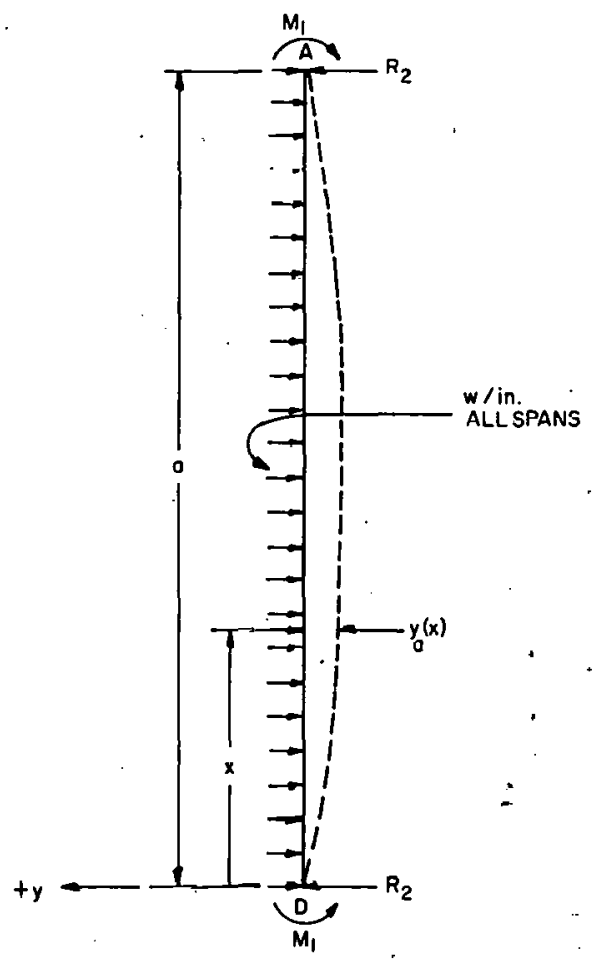

Fig. C.2. Free Body Diagrams of Spans A and B in Cavity Without Side Stays (Axial End Reactions Not Shown). 
From the free body diagrams shown in Fig. C.2, the following equations were obtained.

$$
\begin{aligned}
& R_{1}=\frac{w b}{2} \\
& R_{Q}=\frac{w a}{2} .
\end{aligned}
$$

For span a,

$$
M(x)=-M_{1}+\frac{w a x}{2}-\frac{w x^{2}}{2}
$$

For span b,

$$
M(x)=-M_{1}+\frac{w b x}{2}-\frac{w x^{2}}{2}
$$

The differential equation for the elastic curves has the following general form.

$$
E I \frac{d^{2} y}{d x^{2}}=M(x)
$$

Two or more of the conditions listed below will be needed to solve for the constants of integration. These conditions are

1. $\mathrm{y}=0$ at $\mathrm{A}, \mathrm{B}, \mathrm{C}$, and $\mathrm{D}$;

2. $d y / d x=0$ at $a / 2$ and $b / 2$;

3. for $\operatorname{span}$ a at $D, d y / d x=-\theta_{A}$ at $x=0$; and

4. $\left.\left.\frac{\mathrm{dy}}{\mathrm{dx}}\right]_{L}=\frac{\mathrm{dy}}{\mathrm{dx}}\right]_{R}$.

The fourth condition is an expression of continuity between two beams connected at a joint. The condition is that at the joint of the beams, the slope of the beam on one side of the joint is equal to the slope of the beam on the other side of the joint. This follows from the assumption that the corners (joints) are rigid but that they may rotate.

For span a,

$$
\frac{d^{2} y}{d x^{2}}=\frac{1}{E I_{a}}\left(-M_{1}+\frac{w a x}{2}-\frac{w x^{2}}{2}\right)
$$

Integrating once,

$$
\frac{d y}{d x}=\frac{1}{E I_{a}}\left(-M_{1} x+\frac{w a x^{2}}{4}-\frac{w x^{3}}{6}\right)+C_{1} \text {. }
$$

Condition 3 given above is applied to evaluate $r_{1}$.

$$
\mathrm{C}_{1}=-\theta_{\mathrm{A}} \text {. }
$$


Combining Eqs. C.6 and C.7,

$$
\frac{d y}{d x}=\frac{1}{E I_{a}}\left(-M_{1} x+\frac{w a x^{2}}{4}-\frac{w x^{3}}{6}\right)-\theta_{A},
$$

and integrating again,

$$
y_{a}=\frac{1}{E I_{a}}\left(-\frac{M_{1} x^{2}}{2}+\frac{w a x^{3}}{12}-\frac{w x^{4}}{24}\right)-\theta_{A} x+c_{2} \text {. }
$$

Condition $1, y=0$ at $\mathrm{x}=0$, is applied to evaluate $C_{2}$.

$$
c_{2}=0 \text {. }
$$

Combining Eqs. C.9 and C.10,

$$
\mathrm{y}_{a}=\frac{1}{E I_{a}}\left(-\frac{M_{1} x^{2}}{2}+\frac{w a x^{3}}{12}-\frac{w x^{4}}{24}\right)-\theta_{A} x .
$$

By analogy, for s̀an b,

$$
\frac{d y}{d x}=\frac{1}{E I_{b}}\left(-M_{1} x+\frac{w b x^{2}}{4}-\frac{w x^{3}}{6}\right)+\theta_{A},
$$

and

$$
\mathrm{y}_{\mathrm{b}}=\frac{1}{\mathrm{EI}_{\mathrm{b}}}\left(-\frac{\mathrm{M}_{1} \mathrm{x}^{2}}{2}+\frac{w b x^{3}}{12}-\frac{w x^{4}}{24}\right)+\theta_{A} \mathrm{x} .
$$

To obtain the equation for the moment $M_{1}$, the second condition, $\mathrm{dy} / \mathrm{dx}=0$ at $\mathrm{a} / 2$ and $\mathrm{b} / 2$, is applied to Eq. 6.8 ,

and to Eq. C.12,

$$
\frac{1}{E I_{a}}\left(-\frac{M_{1} a}{2}+\frac{w a^{3}}{24}\right)-\theta_{A}=0 \text {, }
$$

$$
\frac{1}{E I_{b}}\left(-\frac{M_{1} b}{2}+\frac{w b^{3}}{24}\right)+\theta_{A}=0 \text {. }
$$

Rewriting Eqs. C.14 and C.15,

and

$$
-\frac{a}{2 E I_{a}} M_{1}-\theta_{A}=-\frac{w a^{3}}{24 E I_{a}},
$$

$$
-\frac{b}{2 E I_{b}} M_{1}+\theta_{A}=-\frac{w b^{3}}{24 F \cdot I_{b}} .
$$

Adding Eqs. C.16 and C.17, changing signs, and rearranging, the moment

$$
M_{1}=\frac{w}{12}\left(\frac{a^{3} I_{b}+b^{3} T_{a}}{a I_{b}+b I_{a}}\right) .
$$


Substituting the expression for $M_{1}$ given in Eq. 3 into Eq. C.16, the end slope

$$
\theta_{A}=\frac{w a b}{24 E}\left|\frac{a^{2}-b^{2}}{a I_{b}+b I_{a}}\right|
$$

By Substituting the expressions for $M_{1}$ and $\theta_{A}$ given in Eqs. 3 and 4 into Eqs. 1 and 2, the more customary type of expressions for $y_{a}$ and $y_{b}$ without the terms $M_{1}$ and $\theta_{A}$ may be obtained. However, it is simpler to use Eqs. 1 and 2 in their present forms than in the more customary form when one wishes to express them in FORTRAN for computer programming. Since there seems to be no compelling reason to obtain the more customary expressions, we will avoid the algebra and leave Eqs. 1 and 2 in their present form.

At this point it may be worth observing that Eqs. 1 and 2 permit $I_{a}$ to be different from $I_{b}$. We may have been even more general and permitted I to vary along the span and to be different at each side and at the top and bottom. Consideration of the available material, costs, and problems of design and fabrication have led to the belief that it is more practical in at least the case of the prototype of the 50 -Mev "coaxial" radio frequency cavity to use the same size plate and the same size and spacing for the stiffeners all around. This is to say that the flexural rigidity of the walls will be constant all around.

Letting $I_{a}=I_{b}=I$, the moment

$$
M_{1}=\frac{w}{12}\left(a^{2}-a b+b^{2}\right),
$$

and the end slope

$$
\cdot \theta_{A}=\frac{w a b(a-b)}{24 \mathrm{EI}} \text {. }
$$

Substituting Eq. 5 into Eq. 1 and simp1ifying,

$$
y_{a}=\frac{w x}{24 E I}\left[-\left(a^{2}-a b+b^{2}\right) x+2 a x^{2}-x^{3}-a b(a-b)\right],
$$

and substituting Eq. 6 into Eq. 2 and simplifying,

$$
y_{b}=\frac{w x}{24 E I}\left[-\left(a^{2}-a b+b^{3}\right) x+2 b x^{2}-x^{3}+a b(a-b)\right] .
$$

Equations 7 and 8 are expressed in the customary form. 
Expressions of the maximum deflections will be useful. For span a; $y_{\max }$ nrcure at $\mathrm{x}=\mathrm{a} / 2$. Substituting $\mathrm{a} / 2$ for $\mathrm{x}$ in $E q .7$ and simplifying,

$$
y_{a_{\max }}=-\frac{w a^{2}}{384 E I}\left(a^{2}+4 a b-4 b^{2}\right) \text {. }
$$

For $\operatorname{span} b, y_{\max }$ occurs $a t x=b / 2$. Substituting $b / 2$ for $x$ in $E q .8$ and simplifying,

$$
y_{b_{\max }}=-\frac{w b^{2}}{384 E I}(2 a-b)(6 a-5 b) .
$$

An easy check on these derivations may be obtained by letting $I_{a}=$ $I_{b}=I$ and $a=b=l$. Making these substitutions in Eqs. 3, 4, 1, and 2 and performing the appropriate algebriac operations,

$$
\begin{aligned}
& M_{1}=\frac{w l^{3}}{12}, \\
& \dot{\theta}_{A}=0,
\end{aligned}
$$

and

$$
y_{a}=y_{b}=y=-\frac{w x^{2}}{24 E I}(l-x)^{2} .
$$

These are the familiar expressions for the end moments and deflections of a uniformly loaded beam with fully constrained culs. 


\section{Appendix D}

MATHEMATICAL DERIVATION OF ELASTIC CURVES, BENDING MOMENTS, AND END SLOPES FOR CAVITY WITH SIDE STAYS

A cross-sectional slice of unit thickness taken through the cavity with side stays is shown in Fig. D.1. The overall height of the crosssectional slice is denoted by the letter $\ell$, the distance between stays located at points $C$ and $H$ and $G$ and $D$ as $a$, the distance from the stays to either the top or bottom of the cavity as $b$, and the width of the cross-sectional slice as $c$. The slopes at points A, B, C, D, E, F, G, and $\mathrm{H}$ are designated as $\theta_{A}, \theta_{B}, \theta_{C}, \theta_{D}, \theta_{E}, \theta_{F}, \theta_{G}$, and $\theta_{H}$. The loading w lb/in., is the atmospheric pressure all around the outside surface of

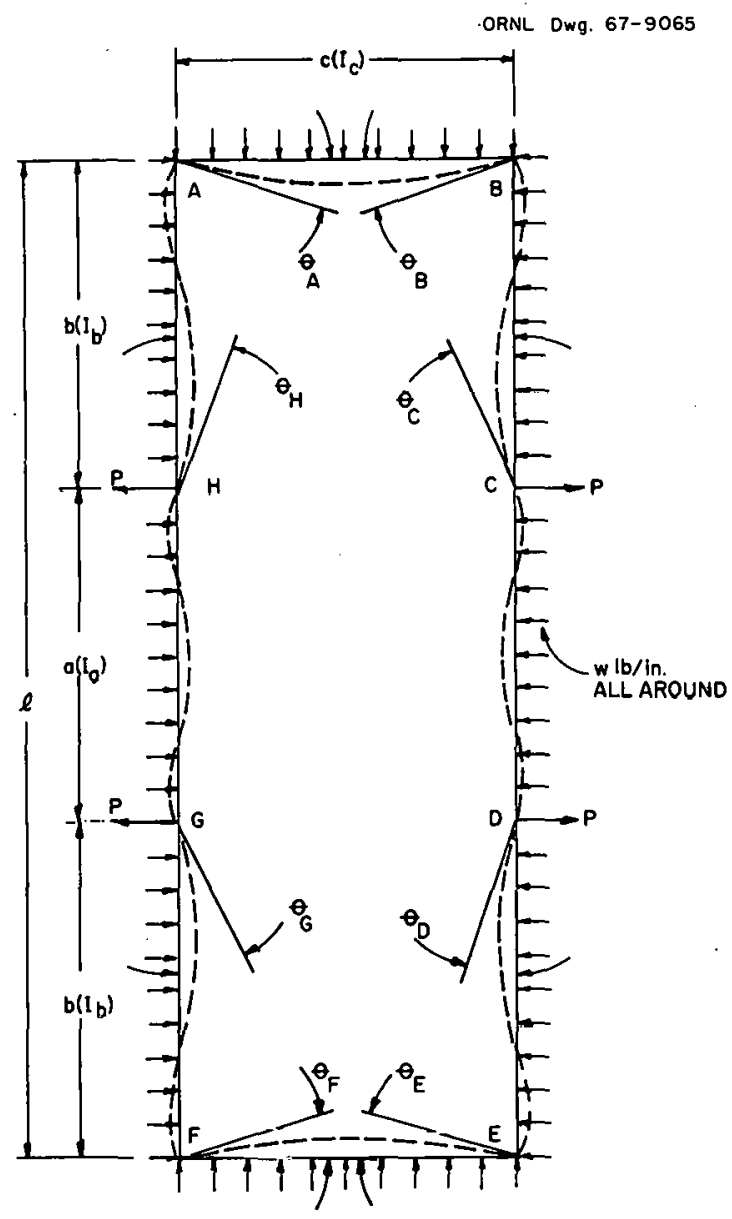

Fig. D. 1. Cross-Sectional Slice of Unit Thickness Through Cavity With Eide Stays. 
the cavity that results when the cavity is evacuated during operation. The plane moments of inertia of the beams with spans $a, b$, and $c$ are $I_{a}, I_{b}$, and $I_{c}$, respectively.

The corners at points $A, B, E$, and $F$ were assumed to be rigid but able to rotate, and the points, A, B, C, D, E, F, G, and $H$ were assumed to remain stationary except for rotations. Therefore,

$$
y(\text { deflection })=0 \text { at } A, B, C, D, E, F, G \text {, and } H \text {, }
$$

and by symmetry

and

$$
\theta_{\mathrm{A}}=\theta_{\mathrm{E}}=-\theta_{\mathrm{B}}=-\theta_{\mathrm{F}}
$$$$
\theta_{\mathrm{D}}=\theta_{\mathrm{HI}}=-\theta_{\mathrm{C}}=-\theta_{\mathrm{G}} \cdot
$$

To obtain expressions for the bending moments and reactions, free body diagrams of spans $a, b$, and $c$ and the load point between spans a and $b$ were drawn, as shown in Fig. D.2. The sign conventinn previouely adopted for the derivations in Appendix $C$ was also applied in this case. From the free body diagrams shown in Fig. D.2, for span $c$ the $\Sigma V=0$ and

$$
\begin{gathered}
w c-2 R_{2}=0 \\
R_{Z}=\frac{W C}{2} .
\end{gathered}
$$

For span b, $\Sigma_{\mathrm{H}}=0$, and

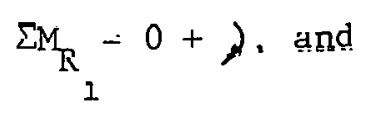

$$
\begin{gathered}
w b-k_{1}-k_{3}=0 . \\
M_{1}-\frac{w b^{C}}{2}+R_{3} b-M_{3}=0 .
\end{gathered}
$$

For span a, $\Sigma \mathrm{H}=0$, and

$$
\begin{gathered}
\text { wa }-2 \mathrm{R}_{4}=0 \\
\mathrm{R}_{ \pm}=\frac{\mathrm{wa}}{2} .
\end{gathered}
$$

For joint $\mathrm{H}, \Sigma_{\mathrm{H}}=0$, and

$$
\mathrm{R}_{3}+\mathrm{R}_{4}-\mathrm{P}=0 \text {. }
$$

Substituting the expression for $\mathrm{R}_{4}$ given in Eq. D.6 into Eq. D.7,

$$
\mathrm{R}_{3}+\frac{\mathrm{Wa}}{2}=\mathrm{P} \text {. }
$$

We may observe from Fig. D.2 that the loadings of spans $a, b$, and $c$ are similar. They each have axial and transverse end reactions, end 


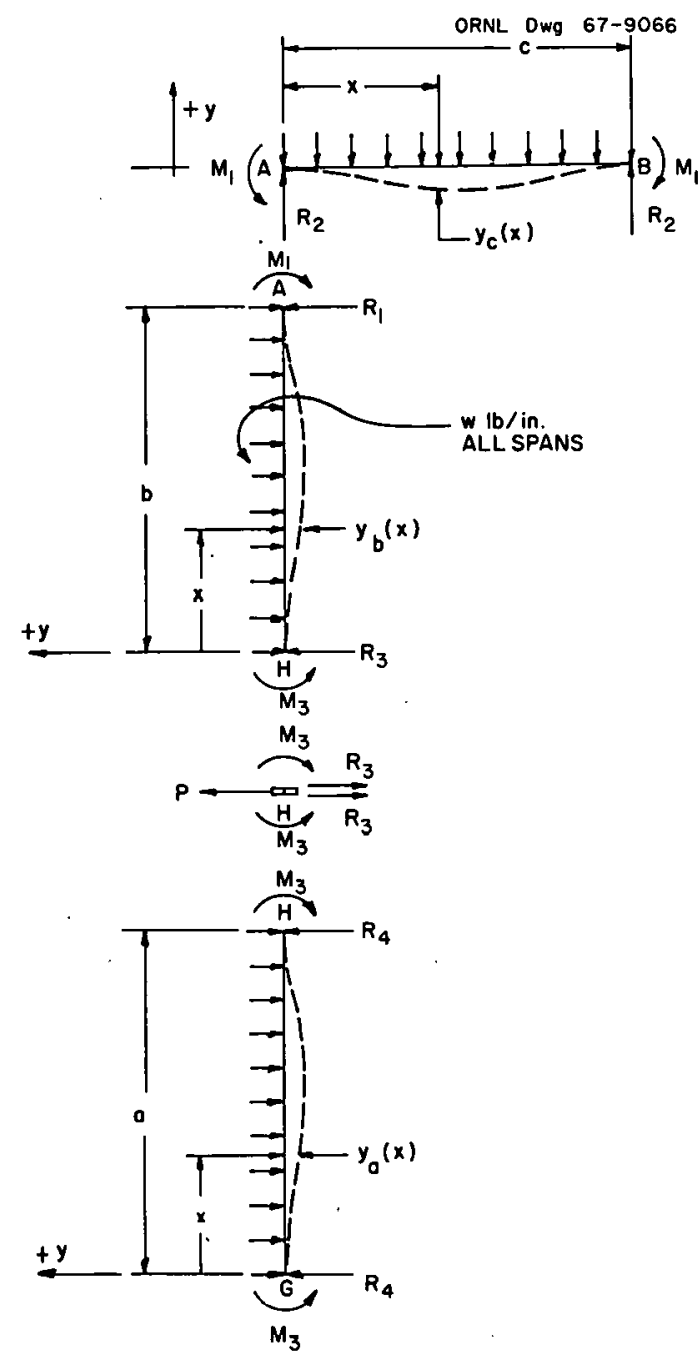

Fig. D.2. Free Body Diagrams of Spans a, b, and $c$ for Cavity With Side Stays. (Axial End Reactions not Shown.)

moments and uniform span loading. We need only to solve one general problem to obtain expressions for the bending moments, end slopes, and the elastic curves that apply to all three spans in general terms. If deflections are small, the bending moments caused by axial end reactions are small when compared with the bending moments caused by transverse loads and reactions. Since the deflections in the cavity must be limited to small ones, we may neglect axial end reactions and simplify the mathematics greatly. The free body diagram of a span labeled in general terms applicable to spans $a, b$, and $c$ is illustrated in Fig. D.3. 


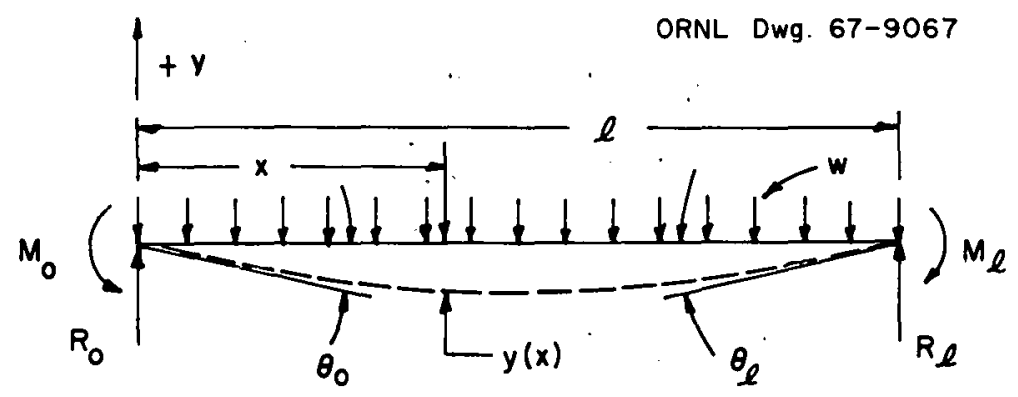

Fig. D.3. Free Body Diagram of a Span Labeled in General Terms.

The differential equation of the elastic curve,

$$
E I \frac{d^{2} y}{d x^{2}}=M(x),
$$

and

$$
M(x)=-M_{0}-\frac{w x^{2}}{2}+R_{0} x .
$$

Substituting the expression for $M(x)$ given in Eq. D.10 into Eq. D.9,

$$
\frac{d^{2} y}{d x^{2}}=\frac{1}{E I}\left|-\frac{w x^{2}}{2}+R_{u} x-M_{u}\right| .
$$

Integrating once,

$$
\frac{d y}{d x}=\frac{1}{E I}\left(-\frac{w x^{7}}{6}+\frac{\tilde{R}_{j} x^{2}}{2}-M_{0} x\right)+C_{1} .
$$

To evaluate $C_{1}$, we apply the condition

$$
\left|\frac{d y}{d x}\right|_{x=0}=\theta_{0}
$$

and

$$
\check{c}_{1}=\theta_{0} \text {. }
$$

Combing Eqs. D. 13 and D.12,

$$
\left|\frac{d y}{d x}\right|=\frac{1}{E I}-\frac{w x^{3}}{6}+\frac{R_{0} x^{2}}{2}-M_{0} x+\theta_{0} \cdot
$$

Integrating again,

$$
y=\frac{1}{E I}\left(-\frac{w x^{4}}{24}+\frac{R_{0} x^{3}}{6}-\frac{M_{0} x^{2}}{2}\right)+\theta_{0} x+C_{2}^{C} .
$$


To evaluate $\mathrm{C}_{2}$, we apply the condition $\mathrm{y}=0$ at $\mathrm{x}=0$, and

$$
\mathrm{C}_{2}=0
$$

Combining Eqs. D. 15 and D. 14,

$$
\left.\mathrm{y}=\frac{1}{\mathrm{EI}} \mid-\frac{\mathrm{wx}}{24}+\frac{\mathrm{R}_{\mathrm{o}} \mathrm{x}^{3}}{6}-\frac{\mathrm{M}_{\mathrm{o}} \mathrm{x}^{2}}{2}\right)+\theta_{\mathrm{o}} \mathrm{x} .
$$

By making simple substitutions in Eqs. D. 14 and D.17, expressions for the end slopes and elastic curves of spans $a, b$, and $c$ may be obtained. For span $a, l=a, \theta_{0}=\theta_{G}, \theta_{l}=\theta_{H}, I=I_{a}, M_{0}=M_{3}$, and $\mathrm{R}_{\mathrm{O}}=\mathrm{R}_{4}=\mathrm{wa} / 2$.

$$
\begin{aligned}
& \left.\frac{d y}{d x}=\frac{1}{E I_{a}} \mid-\frac{w x^{3}}{6}+\frac{w a x^{2}}{4}-M_{3} x\right)+\theta_{G} . \\
& y_{a}=\frac{1}{E I_{a}}\left(-\frac{w x^{4}}{24}+\frac{w a x^{3}}{12}-\frac{M^{2}}{2}\right)+\theta_{G} x .
\end{aligned}
$$

For span $b, \ell=b, \theta_{0}=\theta_{H}=-\theta_{G}, \theta_{\ell}=\theta_{A}, I=I_{b}, M_{0}=M_{3}$, and $R_{0}=R_{3}$.

$$
\begin{aligned}
& \left.\frac{d y}{d x}=\frac{1}{E I_{b}}:-\frac{w x^{3}}{6}+\frac{R x^{2}}{2}-M_{3} x\right)-\theta_{G} . \\
& y_{b}=\frac{1}{E I_{b}}\left(-\frac{w x^{4}}{24}+\frac{R_{3} x^{3}}{6}-\frac{M^{2} x^{2}}{2}\right)-\theta_{G} x .
\end{aligned}
$$

For span $c, \ell=c, \theta_{0}=0_{A}, \theta_{l}=\theta_{B}, I=T_{c}, M_{0}=M_{1}$, and $R_{0}=R_{2}=$ wc/2.

$$
\begin{aligned}
& \frac{\mathrm{dy}}{\mathrm{dx}}=\frac{1}{E I_{c}}\left(-\frac{w x^{3}}{6}+\frac{w c x^{2}}{4}-\mathrm{M}_{1} \mathrm{x}\right)+\theta_{A} . \\
& y_{c}=\frac{1}{E I_{c}}\left(-\frac{w x^{4}}{24}+\frac{w c x^{3}}{12}-\frac{M^{2}}{2}\right)+\theta_{A} x .
\end{aligned}
$$

To find expressions for $M_{1}, M_{3}, R_{3}, \theta_{G}$, and $\theta_{A}$ in terms of $a, b$, $c, I_{a}, I_{b}, I_{c}, E$, and $w$, five equations in these terms will be needed. Applying the condition

$$
\left.\left.\theta_{\mathrm{H}}\right]_{\mathrm{L}}=\theta_{\mathrm{H}}\right]_{\mathrm{R}} \text {, }
$$

setting $x=a$ in Eq. D. 18, and noting that $\theta_{H}=-\theta_{G}$, 


$$
\frac{1}{E_{a}}\left(-\frac{w a^{3}}{G}+\frac{w a^{3}}{4}-M_{3} a\right)+\theta_{G}=-\theta_{G} .
$$

The expressions

$$
\theta_{\mathrm{H}}=\theta_{\mathrm{H}}{ }_{\mathrm{R}} \text { and } \theta_{\mathrm{A}}=\theta_{\mathrm{L}}{ }_{\mathrm{A}}
$$

are expressions of continuity between two beams connected at a joint. They state that at the joint of the beams, the tangent to the beam on one side of the joint is equal to the tangent to the beam on the other side of the joint. This follows from the assumption that the corners and stay points are rigid but may rotate. The subscript $\mathrm{H}$ of the expression $\theta_{H}$ refers to joint $H$ and the subscript $A$ of the expression $\theta_{A}$ refers to joint A. Applying the condition

$$
\theta_{\mathrm{A}}=\left.\theta_{\mathrm{A}}\right|_{\mathrm{R}}
$$

and setting $x=b$ in Eq. D.20,

$$
\frac{1}{E I_{b}}\left(-\frac{w b^{3}}{6}+\frac{R b^{2}}{2}-M_{3} b\right)-\theta_{G}=\theta_{A} \text {. }
$$

Applying the condition $\left.\mathrm{y}_{\mathrm{c}}\right)_{\mathrm{x}}=\mathrm{b}=0$ to Eq. 12 ,

$$
\left.\frac{1}{E I_{b}} \mid-\frac{w b^{4}}{24}+\frac{R_{3} b^{3}}{6}-\frac{M_{3} b^{2}}{2}\right)-\theta_{G} b=0 \text {. }
$$

Applying the condition $\left.y_{c}\right]_{x}=c=0$ to Eq. 13,

$$
\frac{1}{E I_{c}} !-\frac{w c^{4}}{24}+\frac{w c^{4}}{12}-\frac{M_{1} c^{2}}{2} !+\theta_{A} c=0 .
$$

Equation D. 4 containing the terms $M_{1}, M_{3}$, and $R_{3}$ will be used as the fifth equation. Simultaneous solution of Eqs. D.4, D.24, D.25, D.26, and D.27 yields Eqs. 14, D.29, D.30, D.31, and D.32. These cquations give expressions for $R_{i 3}, M_{3}, \theta_{A}, \theta_{G}$, and $M_{\perp}$ in terms of $a, b, c, I_{a}$, $I_{b}, I_{c}, E$, and $w$, and these expressions may be checked by substituting them into the original equations from which they were derived.

$R_{3}=\frac{w\left(a^{3} I_{b}-b^{3} I_{a}\right)\left(b I_{c}+c I_{b}\right)-\left(a I_{b}+b I_{a}\right)\left(c^{3} I_{b}-6 b^{2} c I_{b}-3 b^{3} I_{c}\right)}{4 b\left(2 b I_{c}+3 c I_{b}\right)\left(a I_{b}+b I_{a}\right)-b I_{a}\left(b I_{c}+c I_{b}\right)}$ 


$$
\begin{aligned}
& M_{3}=\frac{w}{12\left(a I_{b}+b I_{a}\right)} \quad\left(a^{3} I_{b}-b^{3} I_{a}+b I_{a}\right) \\
& \frac{\left(a^{3} I_{b}-b^{3} I_{a}\right)\left(b I_{c}+c I_{b}\right)-\left(a I_{b}+b I_{a}\right)\left(c^{3} I_{b}-6 b^{2} c I_{b}-3 b^{3} I_{c}\right)}{\left(2 b I_{c}+3 c I_{b}\right)\left(a I_{b}+b I_{a}\right)-b I_{a}\left(b I_{c}+c I_{b}\right)} \\
& \theta_{A}=\frac{b w}{24 E I_{b}}:\left(2-\frac{b I_{a}}{a I_{b}+b I_{a}}\right) \\
& \left|\frac{\left(a^{3} I_{b}-b^{3} I_{a}\right)\left(b I_{c}+c I_{b}\right)-\left(a I_{b}+b I_{a}\right)\left(c^{3} I_{b}-6 b^{2} c I_{b}-3 b^{3} I_{c}\right)}{\left(2 b I_{c}+3 c I_{b}\right)\left(a I_{b}+b I_{a}\right)-b I_{a}\left(b I_{c}+c I_{b}\right)}\right| \\
& \left.-\frac{a^{3} I_{b}-b^{3} I_{a}}{a I_{b}+b I_{a}}-3 b^{2}\right] \\
& \theta_{G}=\frac{a w}{24 E I_{a}}: \frac{a^{3} I_{b}-b^{3} I_{a}}{a I_{b}+b I_{a}}+\left(\frac{b I_{a}}{a I_{b}+b I_{a}}\right. \\
& \frac{\left(a^{3} I_{b}-b^{3} I_{a}\right)\left(b I_{c}+c I_{b}\right)-\left(a I_{b}+b I_{a}\right)\left(c^{3} I_{b}-6 b^{2} c I_{b}-3 b^{3} I_{c}\right)}{\left(2 b I_{c}+3 c I_{b}\right)\left(a I_{b}+b I_{a}\right)-b I_{a}\left(b I_{c}+c I_{b}\right)}-a^{2} \\
& M_{\perp}=\frac{w}{12 c} \frac{b I}{c}_{I_{b}}\left[\left(2-\frac{b I_{a}}{a I_{b}+b I_{a}}\right)\right. \\
& \left(\frac{\left(a^{3} I_{b}-b^{3} I_{a}\right)\left(b I_{c}+c I_{b}\right)-\left(a I_{b}+b I_{a}\right)\left(c^{3} I_{b}-6 b^{2} c I_{b}-3 b^{3} I_{c}\right)}{\left(2 b I_{c}+3 c I_{b}\right)\left(a I_{b}+b I_{a}\right)-b I_{a}\left(b I_{c}+c I_{b}\right)}\right) \\
& \left.\left.-\frac{a^{3} I_{b}-b^{3} I_{a}}{a I_{b}+b I_{a}}-3 b^{2}\right]+c^{3}\right\}
\end{aligned}
$$

The expressions for $R_{3}, M_{3}, \theta_{A}, \theta_{G}$, and $M$ in Eqs. 14, D.29, D. 30 , D. 31 , and D. 32 may be substituted into Eqs. 11, 12, and 13 to obtain expressions for $y_{a}, y_{b}$, and $y_{c}$ in the customary form. However, it is simpler to use Eqs. 11, 12, and 13 in their present form for FORTRAN computer programming. It is necessary that the expression for $R_{3}$ in 
Eq. 14 be in terms of $a, b, c, I_{a}, I_{b}, I_{c}$, and $w$, but simpler expressions for $M_{3}, \theta_{A}, \theta_{G}$, and $M_{I}$ that are easier to express in FORTRAN and to. handle in manual computations can be obtained. These expressions are given in Eqs. 15, 16, 17, and 18, and the expression for $P$ derived from the solution of Eq. D. 8 is given in Eq. 19.

$$
\begin{gathered}
M_{3}=\frac{w\left(a^{3} I_{b}-b^{3} I_{a}\right)+4 b^{2} I_{a \cdot 3} R}{12\left(a I_{b}+b I_{a}\right)} \\
\theta_{A}=\frac{8 b^{2} R_{3}-12 b M M_{3}-3 w b^{2}}{24 E I_{b}} \\
\theta_{G}=\frac{12 a M_{3}-w a^{3}}{24 E I_{a}} \\
M=\frac{24 E I_{c}{ }_{A}+w c^{3}}{12 c} \\
\perp=\frac{w a}{2}
\end{gathered}
$$

Expressions for the maximum deflections would be useful. However, these are not easily obtained because the marimum dcflecliuns do not necessarily occur at the middle of the span. Expressions of the deflections at mid-span will be obtained on the assumption that for sildil jeflections and reasonable designs, the maximum deflectiou is ifkely to occur at the mid-span of spans $a$ and $c$ and near the mid-span on span $b$.

For span $a, y_{a}$ mid-span occurs at $x=a / 2$. Substituting $a / 2$ for $x$ in Eq. 11 and simplifying,

$$
\mathrm{y}_{\mathrm{a} \text { mid-span }}=\frac{1}{\mathrm{EI}_{\mathrm{a}}}\left(\frac{\mathrm{wa}}{128}-\frac{\mathrm{a}^{2} \mathrm{M}}{8}\right)+\frac{{ }^{a}{ }_{\mathrm{G}}}{2} \text {. }
$$

For span $b, y_{b}$ mid-span occurs at $x=b / 2$. Substituting $b / 2$-for $x$ in Eq. 12 and simplifying,

$$
y_{b \text { mid-span }}=\frac{1}{E I_{b}}\left(-\frac{w b^{4}}{384}+\frac{b^{3} R}{48}-\frac{b^{2} M}{8}\right)-\frac{b \theta_{G}}{2} .
$$

For span $c, y_{c}$ mid-span occurs at $x=c / 2$. Substituting $c / 2$ for $x$ in Eq. 1,3 and simplifying, 


$$
y_{c \text { mid-span }}=\frac{1}{E I_{c}} \frac{w c^{4}}{128}-\frac{M_{c^{2}}}{8}+\frac{{ }^{c} \theta_{A}}{2}
$$

In a particular design case, $a$ is set to equal $b$ and $I_{a}=I_{b}$. Therefore,

$$
\begin{gathered}
R_{3}=\frac{w\left(3 a^{3} I_{c}+6 a^{2} I_{a}-c^{3} I_{a}\right)}{2 a\left(3 a I_{c}+5 c I_{a}\right)}, \\
M_{3}=\frac{a}{6} R_{3}, \\
\theta_{A}=\frac{a^{2}}{8 E I_{a}}\left(2 R_{3}-w a\right), \\
\theta_{G}=\frac{a^{2}}{24 E I_{a}}\left(2 R_{3}-w a\right)=\frac{\theta_{A}}{3}, \\
M_{I}=\frac{24 E I_{c} \theta_{A}+w c^{3}}{12 c},
\end{gathered}
$$

and

$$
P=R_{3}+\frac{w a}{2}
$$

In another design case, $a=b$ and $I_{a}=I_{b}=I_{c}=I$. Eqs. 29 through 34 result from these conditions, and they were obtained from Eqs. 23 through 28 by dropping the subscripts from the terms $I_{a}$ and $I_{c}$ giving $\mathrm{I}$. They are expressed both in the form of the original equations and in terms of $a, c, w, E$, and $T$. In the latter form, the I's cancel out of the expressions for $\mathrm{R}_{3}, \mathrm{M}_{3}, \mathrm{M}_{1}$, and $\mathrm{P}$.

$$
\begin{gathered}
R_{3}=\frac{w\left(3 a^{3}+6 a^{2} c-c^{3}\right)}{2 a(3 a+5 c)} \\
M_{3}=\frac{a}{6} R_{3}=\frac{w\left(3 a^{3}+6 a^{2} c-c^{3}\right)}{12(3 a+5 c)} \\
\left.\theta_{A}=\frac{a^{2}}{8 E I}{ }_{3}-w a\right)=\frac{a c w\left(a^{2}-c^{2}\right)}{8 E I(3 a+5 c)} \\
\theta_{G}=\frac{a^{2}}{24 E I}\left(2 R_{3}-w a\right)=\frac{\theta_{A}}{3}=\frac{a c w\left(a^{2}-c^{2}\right)}{24 E I(3 a+5 c)}
\end{gathered}
$$




$$
\begin{aligned}
& M_{1}=\frac{24 E I \theta_{A}+w c^{3}}{12 c}+\frac{w\left(3 a^{3}+5 c^{3}\right)}{12(3 a+5 c)} \\
& P=R_{3}+\frac{w a}{2}=\frac{w}{2}\left(\frac{6 a^{3}+11 a^{2} c-c^{3}}{3 a+5 c}\right)
\end{aligned}
$$

These derivations may be checked easily by letting $a=b=c=l$ and $I_{a}=I_{b}=I_{c}=I$. Making these substitutions in the set of equations from Eq. 14 and Eqs. D. 29 through D.32; Eq. D. 8, Eq. 11, Eq. 12, 7, ' and Eq. 13; or the set of equations from Eq. 23 through Eq. 28 and performing the appropriate algebriac operations, Eqs. D.53 through D.59 are derived.

$$
\begin{gathered}
R_{3}=\frac{w \ell}{2} \\
M_{3}=\frac{w \ell^{2}}{12} \\
\theta_{A}=0 \\
\theta_{G}=0 \\
M_{I}=\frac{w_{\ell}^{2}}{12}=M_{3} \\
P=w \ell \\
y_{a}=y_{b}=y_{c}=-\frac{w x^{2}}{2 / 1 E I}(\ell-x)^{2}
\end{gathered}
$$

These are the familiar expressions of the end moments and deflections of a uniformly loaded beam with fully constrained ends. 


\section{Internal Distribution}

1. S. E. Beall

2. M. Bender

3. C. E. Bettis

4. F. L. Culler

5. H. G. Duggan

6. D. E. Ferguson

7. W. F. Ferguson

8. F. C. Fitzpatrick

9. W. R. Gal1

10-11. L. N. Howe 11

12. R. S. Livingston

13. J. E. Mann
14. J. A. Martin

15. E. G. Richardson

16. H. E. Seagren

17. D. A. Sunberg

18. W. R. Winsbro

19. N. F. Ziegler

20-21. Central Research Library

22. Document Reference Section

23. GE Division Library

24-33. Laboratory Records Department

34. Laboratory Records, ORNL R. C.

35. ORNL Patent Office

\section{External Distribution}

36-50. Division of Technical Information Extension

51. Laboratory and University Division, USAEC, ORO 